\title{
Temperature and Pressure Derivatives of Elastic Constants With Application to the Mantle
}

\author{
DON L. ANDERSON \\ Seismological Laboratory, California Institute of Technology, Pasadena
}

\begin{abstract}
The temperature and pressure derivatives of the elastic moduli $M$ of solids can be cast into the form of dimensionless logarithmic anharmonic $\{$ DLA $\}$ parameters, $\partial \ln M / \partial \ln \rho=\{M\}$ at constant temperature, pressure, or entropy $(T, P, S)$, where $\rho$ is the density. These parameters show little variation from material to material and are expected to show little variation with temperature at high temperature. Most of the available derivative data for ionic solids has been renormalized and analyzed for dependency on ion type, crystal structure, and other parameters. The $\{$ DLA $\}$ parameters exhibit little variation and little correlation with crystal structure for most close-packed halides and oxides. There are small systematic variations with ionic radius, Grüneisen's $\gamma$, and the bulk modulus-rigidity ratio $(K / G)$. Temperature and pressure derivatives are correlated because of the importance of the volume-dependent, or extrinsic, terms. The intrinsic terms $\{K\}_{V}$ and $\{G\}_{V}$ are also highly correlated, even for open-packed structures, where $\partial \ln M / \alpha \partial T=\left\{M_{\gamma}\right.$. These correlations make it possible to estimate the derivatives of highpressure phases. The spinel forms of olivine are predicted to have "normal" derivatives, and therefore the magnitude of the modulus or velocity jump associated with the olivine-spinel transition near $400 \mathrm{~km}$ should be similar to that measured in the laboratory. The actual size of the $400-\mathrm{km}$ discontinuity is much less, indicating the presence of substantial quantities of minerals other than olivine in the upper mantle or transition region. Recent calculations in apparent support of a homogeneous olivine-rich $(>60 \%)$ mantle are based on choices for the derivatives of $\beta$ - and $\gamma-\mathrm{Mg}_{2} \mathrm{SiO}_{4}$, which are unlike other ionic crystals. There is no evidence that these phases should be anomalous in their physical properties. The temperature and pressure derivatives of ionic crystals depend on the nature of the ions and their coordination.
\end{abstract}

\section{INTRODUCTION}

Some information is now available on the elastic constants of most of the minerals, including high-pressure phases, which are important in the mantle. What is lacking for the highpressure phases is information regarding the pressure and temperature derivatives of the elastic moduli. These derivatives exhibit relatively little variation amongst ionic solids, and some studies of mantle mineralogy have adopted "normal" values for these parameters [e.g., D. L. Anderson, 1967a, 1970; Bass and Anderson, 1984; Lees et al., 1983]. These studies tend to agree that an isochemical olivine-orthopyroxene-rich mantle is not a completely satisfactory match to seismic profiles. Other studies have adopted anomalous values for the properties of the high-pressure phases in attempts to match the seismic profiles with a homogeneous peridotite mantle [e.g., Weidner, 1985, 1986; Bina and Wood, 1986, 1987]. Because of the low compressibility and thermal expansion and limited availability of high-pressure phases it will be some time before accurate derivatives are available. It is therefore important to devise methods to estimate these parameters either by theoretical or empirical means. First principal, or ab initio, calculations are not yet accurate enough to determine the derivatives with any useful precision. However, there are numerous measurements on a variety of other ionic crystals, and it is therefore appropriate to take an empirical approach to see if any general rules can be formulated. The temperature and pressure derivatives of elastic moduli are basically anharmonic properties and are therefore less amenable to calculation than the first-order elastic moduli. On the other hand, appropriately normalized anharmonic properties tend to be relatively constant with temperature and to vary little from

\footnotetext{
Copyright 1988 by the American Geophysical Union.
}

Paper number $7 \mathrm{~B} 1053$.

0148-0227/88/007B-1053\$05.00 material to material. Also, elastic and thermal properties tend to be constant at constant volume and to vary with volume, at constant temperature or at constant pressure, in a systematic way. By investigating a large number of compounds we should be able to discern any dependence on composition and crystal structure and any correlation with other parameters. Materials with anomalous derivatives are generally anomalous in other respects, and one can test the hypothesis that the spinel forms of olivine have unusual behavior with temperature or pressure.

Lees et al. [1983] and Anderson and Bass [1986] calculated seismic profiles for the upper mantle and showed that olivinerich materials were too fast below the $400-\mathrm{km}$ discontinuity. On the other hand, Weidner [1986] and Bina and Wood [1987] concluded that an olivine-rich composition was a satisfactory fit to the seismic velocities in the transition region. The discrepancy is largely due to the choice of temperature and pressure derivatives for the $\beta$ - and $\gamma$-spinel phases of olivine.

Figure 1 shows how the bulk modulus and shear modulus increases $\Delta K_{s}$ and $\Delta G$ associated with the $\alpha \rightarrow \beta$ phase change at $400 \mathrm{~km}$ depend on the choice of temperature and pressure derivatives adopted for the spinel phase. The dashed line shows the present results based on systematics of the normalized parameters. The first segment of each line shows the effect of a $1600^{\circ} \mathrm{C}$ temperature increase, approximately the temperature increase expected from the surface to $400 \mathrm{~km}$. With the parameters derived in the present paper the temperature derivatives are about the same for the $\alpha$ and $\beta$ phases so there is little change of $\Delta G$ and $\Delta K_{s}$ with temperature. In fact, $\partial K_{s} / \partial T$ and $\partial G / \partial T$ are remarkably constant for a wide variety of materials. Average values, derived in this paper, are $-0.17 \pm 0.10$ and $-0.11 \pm 0.06$ kbar $K^{-1}$, respectively (Table 3). Bina and Wood [1987] (hereafter referred to as BW) choose to treat $(\partial \ln M / \partial T)_{P}$ as a constant, and this serves to reduce substantially the $\partial M / \partial T$ of $\beta$ relative to $\alpha$, causing $\Delta K_{\mathrm{S}}$ and $\Delta G$ to decrease rapidly with temperature. Weidner [1986] 


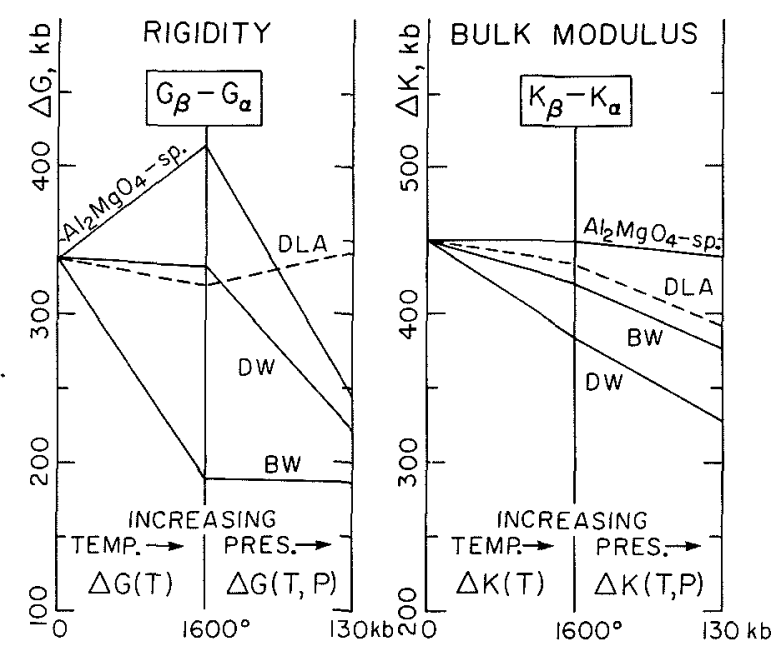

Fig. 1. The difference in rigidity $\Delta G$ and bulk modulus $\Delta K$ between $\alpha$ - and $\beta-\mathrm{Mg}_{2} \mathrm{SiO}_{4}$ as a function of temperature and pressure using the parameters, for $\beta$-spinel, from $\mathrm{DW}$ and $\mathrm{BW}$ and the present study (DLA). Also shown are results for $\mathrm{Al}_{2} \mathrm{MgO}_{4}$-spinel derivatives.

(hereafter referred to as DW) uses an even lower $\partial K_{S} / \partial T$ for $\beta$ relative to $\alpha$, causing $\Delta K_{S}$ to shrink rapidly with temperature. DW adopts a very low $\partial G / \partial P$ for $\beta$, and therefore $\Delta G$ decreases rapidly with pressure. Most of the reduction in $\Delta G$ is due to temperature effects of $\mathrm{BW}$ and pressure effects of DW. $D W$ argues that a low $\partial G / \partial P$ for $\beta$ is justified by the low values for $\mathrm{MgAl}_{2} \mathrm{O}_{4}$-spinel (herafter referred to as spinel). However, if we adopt all of the temperature and pressure derivatives for spinel, we obtain the curve shown. The low $\partial G / \partial P$ is counteracted to some extent by the low $\partial G / \partial T$, which causes the properties of olivine and spinel to diverge at high temperature. The $K_{S}$ derivatives for spinel contrive to give little variation of $\Delta K_{S}$ with temperature and pressure. The net effect, if one wants to adopt the spinel analogy, is to give a much larger $\Delta V_{P}$ at $400 \mathrm{~km}$ than calculated by $\mathrm{DW}$ with a selective use of spinel parameters. This uncertainty in the derivatives for the high-pressure forms of olivine motivated the present paper.

\section{Dimensionless Anharmonic Properties}

It is convenient to treat thermodynamic parameters, including elastic moduli, in terms of volume- and temperaturedependent parts, as in the Mie-Grüneisen equation of state. This is facilitated by the introduction of dimensionless anharmonic parameters. The Grüneisen ratio $\gamma$ is such a parameter. The ratios $\partial K / \partial P=K^{\prime}$ and $\partial G / \partial P=G^{\prime}$ are also dimensionless anharmonic parameters, but it is useful to replace pressure and temperature by volume. This is done by forming logarithmic derivatives with respect to volume or density, giving dimensionless logarithmic anharmonic (DLA) parameters. They are formed as follows

$$
\begin{gathered}
(\partial \ln M / \partial \ln \rho)_{T}=\left(K_{T} / M\right)(\partial M / \partial P)_{T}=\{M\}_{T} \\
(\partial \ln M / \partial \ln \rho)_{P}=(a M)^{-1}(\partial M / \partial T)_{P}=\{M\}_{P} \\
(\partial \ln M / \alpha \partial T)_{V}=\{M\}_{T}-\{M\}_{P}=\{M\}_{V}
\end{gathered}
$$

where we use braces to denote DLA parameters and the subscripts $T, P, V$, and $S$ to denote isothermal, isobaric, isovolume, and adiabatic conditions, respectively. The \{\}$_{V}$ terms are known as intrinsic derivatives, giving the effect of temperature or pressure at constant volume. Elastic, thermal, and anharmonic parameters are relatively independent of temperature at constant volume [Wallace, 1972], particularly at high temperature. This simplifies temperature corrections for the elastic moduli. We use density rather than volume in order to make most of the parameters positive. By high temperature we mean $T>\theta$, where $\theta$ is the Debye or Einstein temperature. The Grüneisen parameter $\gamma$ is generally relatively constant over a broader temperature range than other thermal parameters such as $\alpha$ and $C_{p}$.

The DLA parameters relate the variation of the moduli to volume or density, rather than to temperature and pressure. This is useful since the variations of density with temperature, pressure, composition, and phase are fairly well understood. Furthermore, anharmonic properties tend to be independent of $T$ and $P$ at constant $V$. The anharmonic parameter known as the thermal Grüneisen parameter $\gamma$ is relatively constant from material to material and is relatively independent of temperature.

The parameter $\{K\}_{P}$ played a prominent role in early discussions of the thermal properties of solids [e.g., Grüneisen, 1926; Fürth, 1944; Brillouin, 1964; Gilvarry, 1957]. In recent literature it is given the symbol $\eta$ [Gilvarry, 1957] or $\delta$ [O. L. Anderson, 1967; Birch, 1968] and called the Grüneisen-Anderson [e.g., Sumino and Anderson, 1984] or Anderson-Grüneisen [e.g., Suzuki and Anderson, 1983] parameter or the second Grüneisen parameter $[D$. L. Anderson, $1987 a]$. Grüneisen type parameters play a central role in the seismic equation of state [D. L. Anderson, 1967b, 1987a] and in temperature-dependent equations of state. They express the variation of elastic moduli in terms of volume and with other external parameters at constant volume.

The $\{$ DLA $\}$ parameter $\left\{K_{T}\right\}_{T}$ is simply $\left(\partial K_{T} / \partial P\right)_{T}=K_{T}{ }^{\prime}$. It is easy to show that this depends only on the repulsive range parameter in a central force model of the interatomic potential. Structural and chemical effects, such as the Madelung constant and the valencies, cancel out. The range parameter is either a constant for a given cation-anion interaction or is a smooth function of the interatomic distance. It also varies little from material to material. Accordingly, $\left\{K_{T}\right\}_{T}$ exhibits little variation and, as we shall see, is the most constant of the \{DLA\} parameters. The average and standard deviation for 54 ionic crystals is $5.3 \pm 1.0$. The range is even less for materials with cations most relevant to mantle chemistry. For most materials, $\left\{K_{S}\right\}_{T}$ is close to $\left\{K_{T}\right\}_{T}$.

For an ionic crystal with a Born power law repulsive potential the bulk modulus is [e.g., Anderson and Anderson, 1970]

$$
K V_{0}=A z_{1} z_{2} e^{2}(n-1) / 9 r_{0}
$$

where $A$ is the Madelung constant which depends on crystal structure, $z_{1} z_{2}$ is the valence product, $V_{0}$ and $r_{0}$ are measures of the interatomic spacing, $e$ is the charge on the electron, and $n$ is the power law exponent. The other moduli are similar functions of these parameters. Most of these parameters cancel out in the pressure derivative of the bulk modulus which becomes at $P=0$,

$$
(\partial K / \partial P)_{0}=(\partial \ln K / \partial \ln \rho)_{T}=(n+7) / 3
$$

The repulsive parameter $n$ is a function of ionic radius [Anderson and Anderson, 1970]. All other measures of chemistry and crystal structure have disappeared. A large part of the temperature effect, the volume-dependent part, can also be estimated from the pressure derivatives, and it remains, then, to determine the intrinsic temperature derivatives. Relationships between $\{K\}_{P}$ and $\{K\}_{T}$ are given by D. L. Anderson [1967b]. 
The relative variance of the $\{$ DLA $\}$ parameters increases in the order $\left\{K_{T}\right\}_{T} \sim\left\{K_{S}\right\}_{T}<\left\{K_{T}\right\}_{P}<\{G\}_{P}<\left\{K_{S}\right\}_{P}<\{G\}_{T}$ when considering all available data on ionic solids; that is, $\{G\}_{T}$ shows more variation from material to material than $\{K\}_{T}$. The fractional variation from material to material is comparable to that exhibited by $\gamma$ and $K_{S} / G$, and there are correlations between some of these parameters.

\section{Data}

In order to calculate the complete set of DLA parameters we need measurements of the moduli, their variation with $T$ and $P$, and the coefficient of thermal expansion $\alpha$. These measurements exist for about 60 ionic solids.

The basic data set used in this paper is from the compilation of elastic properties by Sumino and Anderson [1984]. The data consist of 63 measurements on 54 compounds including halides, oxides, and silicates and various structures including rock salt, $\mathrm{CsCl}, \mathrm{ZnS}$, ilmenite (corundum), garnet, perovskite, spinel, quartz, rutile, and fluorite. The measurements compiled include $\alpha$, the elastic moduli, their temperature and pressure derivatives, and the thermal Grüneisen parameter. We focus our attention primarily on close-packed ionic solids which do not contain transition elements; this reduces the data set to 50 compounds. The main exceptions are the garnets which are the most abundant iron-rich mineral in the mantle. It must be kept in mind that the properties attributed to garnets may reflect the presence of $\mathrm{Fe}^{2+}$ rather than being properties of the garnet structure. We also include some $\mathrm{Zn}$ - and Ti-bearing compounds.

We first renormalize all pressure and temperature derivatives to logarithmic volume derivatives. As expected, these show less variation than the unnormalized forms. We then form the intrinsic, or constant volume, derivatives, which are denoted by \{\}$_{v}$. We now have eight DLA parameters for each compound. Some of these parameters show more variation from material to material than others, so we seek correlations and combinations that might allow tighter bounds to be placed on the properties of unmeasured compounds. Two useful combinations are $\{K\}_{V}-\{G\}_{V}$ and $\{K\} /\{G\} \equiv\{K / G\}$. Furthermore, we seek correlations with other parameters such as $K / G$ and $\gamma$ which are available for more compounds. Finally, we arrange the parameters in periodic tables so that chemical effects can be more easily isolated. These gyrations are necessary because we do not have a complete set of measurements on any compound in two crystal structures. We must therefore identify chemical trends before we can discuss structural effects, if any.

The complete set of dimensionless logarithmic anharmonic parameters is given in Table 1 , and various subsets are given in Tables 2-5 and Figures 2-5. The various trends and correlations can be summarized by the general rules in Table 6 .

Table 2 gives average values for various crystal and chemical classes and the grand average for 54 compounds. For comparison, the values for olivine and spinel and the predictions for $\beta$-spinel by DW and BW are also given. The values of $\{M\}_{V}$ should be viewed in the context that a $10-20 \%$ uncertainty in $\{M\}_{T}$ and $\{M\}_{P}$ gives an uncertainty in $\{M\}_{V}$ of 1-2.

Figure 2 shows the normalized pressure derivative of rigidity, $\{G\}_{T}$, versus $K_{S} / G$, which demonstrates the systematic variation of these two parameters and the correlation with ionic radius and $\gamma$. The large boxes enclose the values for the alkali halide rock salt structures with common cations. Note the large variation of $\{G\}_{T}$ for common crystal structures. The small squares give values adopted for $\beta$ - and $\gamma$-spinel by DW and $\mathrm{BW}$. Both sets fall below other silicates.

The $\{G\}_{T}$ versus $\{G\}_{P}$ relation is shown in Figure 3. Silicates and most ${ }^{\text {vi }} \mathrm{M}^{2+}$ oxides fall in the restricted area shown. Note that ${ }^{i v} \mathrm{BeO}$ and ${ }^{\mathrm{iv}} \mathrm{MgAl}_{2} \mathrm{O}_{4}$-spinel are anomalous. The values of DW and $\mathrm{BW}$ are also discrepant, being neither silicatelike nor spinellike. The Ti-bearing compounds have high $\{G\}_{p}$, regardless of crystal structure. This is a characteristic of many crystals with transition element cations. The averages and standard deviations for "geophysically important" compounds (oxides, silicates, halides, and fluorides with cation radii between 0.6 and $1.0 \AA$ ) are $\{G\}_{P}=6.0 \pm 14 \%$ and $\left\{G_{T}=3.1 \pm 23 \%\right.$.

The $\left\{K_{T}\right\}_{V}$ versus $\{G\}_{V}$ relation is shown in Figure 4. Note the coherent behavior of a large number of crystal structures and compositions. Quartz, orthopyroxene, $\mathrm{BaO}$, and $\mathrm{TiO}_{2}$ are anomalous in their individual $\{D L A\}$ parameters but have the same $\left\{K_{T}\right\}_{V}:\{G\}_{V}$ trend. Garnets, $\mathrm{SrTiO}_{3}$, and some rutiles have high $\{G\}_{V}$ for a given $\left\{K_{T}\right\}_{V}$. Note the location of the DW and BW parameters, particularly relative to olivine, spinel and other silicates. Note the intermingling of the oxides and halides. Ti-bearing compounds have low $\left\{K_{T}\right\}_{V}$ and $\{G\}_{V}$. High mean atomic weight $(\bar{M})$ and high-coordination compounds fall below the line. The locations of quartz, Opx, $\mathrm{CaCO}_{3}$, garnets, and rutiles may indicate a role for crystal structure.

Figure 5 shows the systematic behavior of the normalized shear properties of minerals; $\{G\}_{T},\left\{K_{S} / G\right\}_{T}=K_{S}{ }^{\prime} G / G^{\prime} K_{S}$, and $K_{S} / G$. In general, $\{G\}_{T}$ and $\left\{G / K_{S}\right\}_{T}$ increase with an increase in anion radius and decrease with cation radius. $K_{S} / G$ increases with both an increase in anion and cation radius. For a given cation and crystal structure there is little variation in the normalized shear properties.

The properties of the fluorites are nearly continuous with the rock salts, but the corundums and the rutiles (ignoring ionic radius) represent slight discontinuities in the trends. The $\mathrm{CsCl}$ structures represent a major discontinuity. They would fit in better at the top of the rock salt structures, with an effective cationic radius of about 0.6 instead of $\sim 1.6$, or a large anion radius. The corundums have behavior similar to the smaller ion rock salt fluorides and oxides ( $\mathrm{LiF}, \mathrm{MgO}$, $\mathrm{NaF}$ ). On the other hand, the rutiles, although having small cations $(0.4-0.8 \AA)$, represent an extension of the rock salt series to a larger effective cation radius $(>1.5 \AA)$. Numerically, $\left\{K_{S} / G\right\}_{T}$ is about twice the cation radius for the fluorite and rock salt structures, about 3 times for the corundums, and $2 / 3$ for the $\mathrm{CsCl}$ structures. The four coordinated structures (quartz, $\mathrm{BeO}, \mathrm{ZnO}, \mathrm{Al}_{2} \mathrm{MgO}_{4}$ ) have anomalous behavior and generally low $\{G\}_{T}$. Note that the $\mathrm{Zn}$ compounds have low or negative $\{G\}_{T}$, very high $K_{S} / G$, and anomalous $\left\{K_{S} / G\right\}_{T}$. Tibearing compounds $\left(\mathrm{TiO}_{2}, \mathrm{Ti}_{2} \mathrm{O}_{3}, \mathrm{SrTiO}_{3}\right)$, although satisfying the trends for these shear properties, have high $\{G\}_{P}$. This suggests that the nature of the cation affects the shear properties. Note that $\mathrm{Ti}$ and $\mathrm{Zn}$ are transition elements. Transition element bearing ionic solids also have high $K_{\mathrm{S}} / G$.

It might be expected that the shear properties of solids would be sensitive to subtle differences in crystal structure and the influence of noncentral forces. However, the DLA shear parameters are remarkably similar for a variety of structures. For example, $\{G\}_{T}$ has essentially the same mean value for rock salt halides and oxides, garnets, perovskites, fluorites, $\mathrm{Al}_{2} \mathrm{O}_{3}$, and olivine. However, rutiles, particularly those with transition element cations, are lower and $\mathrm{CsCl}$ structures are higher. It is not clear if this is a structural, coordination, or chemical effect. $\{G\}_{P}$ is more variable but olivines, $\mathrm{CsCl}$ struc- 
TABLE 1. Dimensionless Logarithmic Anharmonic Parameters

\begin{tabular}{|c|c|c|c|c|c|c|c|c|c|c|c|c|c|c|c|}
\hline & \multirow{2}{*}{$10^{-6} \mathrm{~K}^{-1}$} & \multirow{2}{*}{$\begin{array}{l}K_{S} \\
\text { kbar }\end{array}$} & \multirow{2}{*}{$\begin{array}{l}G \text {, } \\
\text { kbar }\end{array}$} & $\multirow[b]{2}{*}{K_{S}}_{T}$ & $\multirow[b]{2}{*}{G}_{T}$ & $\multirow[b]{2}{*}{K_{T}}_{P}$ & $\multirow[b]{2}{*}{K_{S}}_{P}$ & $\multirow[b]{2}{*}{G}_{P}$ & $\multirow[b]{2}{*}{K_{T}}_{V}$ & $\multirow[b]{2}{*}{K_{S}}_{V}$ & $\multirow[b]{2}{*}{G}_{V}$ & $\multirow[b]{2}{*}{K-G}_{V}$ & & & \\
\hline & & & & & & & & & & & & & $K_{S} / G$ & Thermal & Acoustic \\
\hline $\mathrm{LiF}$ & 98 & 723 & 485 & 4.90 & 3.97 & 4.69 & 2.42 & 6.35 & 0.5 & 2.5 & -2.4 & 4.9 & 1.49 & 1.66 & 1.92 \\
\hline $\mathrm{NaF}$ & 98 & 483 & 314 & 4.96 & 2.62 & 5.80 & 3.75 & 5.06 & -0.6 & 1.2 & -2.4 & 3.6 & 1.54 & 1.51 & 1.37 \\
\hline $\mathrm{KF}$ & 99 & 318 & 164 & 4.81 & 1.97 & 5.05 & 3.18 & 6.17 & 0.0 & 1.6 & -4.2 & 5.8 & 1.94 & 1.50 & 1.12 \\
\hline $\mathrm{RbF}$ & 95 & 280 & 127 & 5.35 & 1.63 & 4.77 & 2.97 & 5.95 & 0.8 & 2.4 & -4.3 & 6.7 & 2.20 & 1.43 & 1.05 \\
\hline $\mathrm{LiCl}$ & 134 & 318 & 193 & 4.65 & 4.45 & 5.40 & 3.32 & 6.84 & -0.4 & 1.3 & -2.4 & 3.7 & 1.65 & 1.82 & 2.11 \\
\hline $\mathrm{NaCl}$ & 118 & 252 & 148 & 5.10 & 3.00 & 5.45 & 3.74 & 5.07 & -0.1 & 1.4 & -2.1 & 3.4 & 1.71 & 1.51 & 1.55 \\
\hline $\mathrm{KCl}$ & 105 & 181 & 93 & 5.10 & 2.01 & 7.48 & 5.67 & 5.54 & -2.0 & -0.6 & -3.5 & 3.0 & 1.95 & 1.39 & 1.17 \\
\hline $\mathrm{RbCl}$ & 119 & 163 & 78 & 5.09 & 1.79 & 5.81 & 4.11 & 5.30 & -0.4 & 1.0 & -3.5 & 4.5 & 2.10 & 1.44 & 1.09 \\
\hline $\mathrm{AgCl}$ & 93 & 440 & 81 & 6.21 & 2.83 & 10.6 & 7.94 & 11.0 & -3.8 & -1.7 & -8.2 & 6.5 & 5.44 & 2.08 & 1.77 \\
\hline $\mathrm{NaBr}$ & 135 & 207 & 114 & 4.63 & 3.15 & 7.34 & 5.28 & 4.24 & -2.2 & -0.7 & -1.1 & 0.4 & 1.81 & 1.72 & 1.59 \\
\hline $\mathrm{KBr}$ & 116 & 150 & 79 & 5.12 & 2.01 & 5.64 & 3.94 & 4.68 & -0.2 & 1.2 & -2.7 & 3.8 & 1.90 & 1.45 & 1.16 \\
\hline $\mathrm{RbBr}$ & 113 & 137 & 65 & 5.05 & 1.81 & 6.27 & 4.54 & 5.96 & -0.9 & 0.5 & -4.2 & 4.7 & 2.09 & 1.47 & 1.09 \\
\hline $\mathrm{Nal}$ & 138 & 161 & 91 & 5.11 & 3.22 & 4.79 & 2.75 & 5.41 & 0.6 & 2.4 & -2.2 & 4.5 & 1.76 & 1.74 & 1.65 \\
\hline KI & 126 & 122 & 60 & 4.82 & 2.29 & 5.95 & 4.05 & 4.89 & -0.8 & 0.8 & -2.6 & 3.4 & 2.02 & 1.41 & 1.26 \\
\hline $\mathrm{RbI}$ & 119 & 111 & 50 & 5.14 & 1.97 & 6.17 & 4.49 & 6.05 & -0.7 & 0.6 & -4.1 & 4.7 & 2.21 & 1.51 & 1.17 \\
\hline $\mathrm{CsCl}$ & 140 & 182 & 101 & 5.20 & 4.75 & 6.28 & 3.82 & 6.01 & -0.6 & 1.4 & -1.3 & 2.6 & 1.80 & 2.04 & 2.30 \\
\hline $\mathrm{TlCl}$ & 158 & 240 & 92 & 6.00 & 4.45 & 7.78 & 5.18 & 7.35 & -1.0 & 0.8 & -2.9 & 3.7 & 2.60 & 2.46 & 2.31 \\
\hline $\mathrm{CsBr}$ & 138 & 156 & 88 & 4.97 & 4.53 & 6.33 & 3.86 & 5.90 & -0.9 & 1.1 & -1.4 & 2.5 & 1.76 & 1.98 & 2.18 \\
\hline $\mathrm{TlBr}$ & 170 & 224 & 88 & 5.80 & 5.39 & 7.51 & 4.75 & 6.36 & -0.8 & 1.1 & -1.0 & 2.0 & 2.55 & 2.76 & 2.66 \\
\hline CsI & 138 & 126 & 72 & 5.06 & 4.51 & 6.40 & 3.86 & 6.89 & -0.9 & 1.2 & -1.6 & 2.8 & 1.73 & 1.94 & 2.18 \\
\hline $\mathrm{MgO}$ & 31 & 1628 & 1308 & 3.80 & 3.01 & 5.48 & 3.04 & 5.81 & -1.6 & 0.8 & -2.8 & 3.6 & 1.24 & 1.52 & 1.41 \\
\hline $\mathrm{CaO}$ & 29 & 1125 & 810 & 4.78 & 2.42 & 5.45 & 3.92 & 6.29 & -0.6 & 0.9 & -3.9 & 4.7 & 1.39 & 1.27 & 1.25 \\
\hline $\mathrm{SrO}$ & 42 & 912 & 587 & 5.07 & 2.25 & 6.99 & 4.68 & 4.98 & -1.8 & 0.4 & -2.7 & 3.1 & 1.55 & 1.74 & 1.22 \\
\hline $\mathrm{BaO}$ & 38 & 720 & 367 & 5.42 & 1.95 & 9.46 & 7.34 & 7.88 & -3.9 & -1.9 & -5.9 & 4.0 & 1.96 & 1.56 & 1.17 \\
\hline $\mathrm{Al}_{2} \mathrm{O}_{3}$ & 16 & 2512 & 1634 & 4.34 & 2.71 & 6.84 & 4.31 & 7.45 & -2.5 & 0.0 & -4.7 & 4.8 & 1.54 & 1.27 & 1.33 \\
\hline $\mathrm{Ti}_{2} \mathrm{O}_{3}$ & 17 & 2076 & 945 & 4.10 & 2.23 & 7.78 & 6.66 & 12.9 & -3.6 & -2.6 & -11 & 8.2 & 2.20 & 1.13 & 1.15 \\
\hline $\mathrm{Fe}_{2} \mathrm{O}_{3}$ & 33 & 2066 & 910 & 4.44 & 1.63 & 5.70 & 3.68 & 3.34 & -1.2 & 0.8 & -1.7 & 2.5 & 2.27 & 1.99 & 0.95 \\
\hline $\mathrm{TiO}_{2}$ & 24 & 2140 & 1120 & 6.83 & 1.09 & 12.7 & 10.5 & 8.37 & -5.7 & -3.7 & -7.3 & 3.6 & 1.91 & 1.72 & 0.96 \\
\hline $\mathrm{GeO}_{2}$ & 14 & 2589 & 1509 & 6.12 & 2.10 & 11.9 & 10.2 & 5.83 & -5.7 & -4.1 & -3.7 & -0.3 & 1.72 & 1.17 & 1.27 \\
\hline $\mathrm{SnO}_{2}$ & 10 & 2123 & 1017 & 5.09 & 1.25 & 9.90 & 8.64 & 6.21 & -4.8 & -3.6 & -5.0 & 1.4 & 2.09 & 0.88 & 0.85 \\
\hline $\mathrm{MF}_{2}$ & 38 & 1019 & 547 & 5.01 & 1.34 & 5.36 & 4.17 & 3.83 & -0.3 & 0.8 & -2.5 & 3.3 & 1.86 & 1.22 & 0.87 \\
\hline $\mathrm{NiF}_{2}$ & 23 & 1207 & 459 & 4.98 & -1.4 & 8.80 & 7.47 & 1.96 & -3.8 & -2.5 & -3.4 & 0.9 & 2.63 & 0.88 & -0.2 \\
\hline $\mathrm{ZnF}_{2}$ & 29 & 1052 & 394 & 4.51 & 0.13 & 9.49 & 8.23 & 4.73 & -4.9 & -3.7 & -4.6 & 0.9 & 2.67 & 0.97 & 0.39 \\
\hline $\mathrm{CaF}_{2}$ & 61 & 845 & 427 & 4.55 & 2.26 & 5.85 & 3.86 & 4.75 & -1.1 & 0.7 & -2.5 & 3.2 & 1.98 & 1.83 & 1.21 \\
\hline $\mathrm{SrF}_{2}$ & 47 & 714 & 350 & 4.67 & 1.66 & 6.02 & 4.75 & 4.94 & -1.2 & -0.1 & -3.3 & 3.2 & 2.04 & 1.30 & 0.98 \\
\hline $\mathrm{CdF}_{2}$ & 66 & 1054 & 330 & 5.77 & 4.05 & 8.36 & 6.04 & 7.11 & -2.2 & -0.3 & -3.1 & 2.8 & 3.19 & 2.45 & 2.10 \\
\hline $\mathrm{BaF}_{2}$ & 61 & 581 & 255 & 4.89 & 0.88 & 6.52 & 4.54 & 3.83 & -1.4 & 0.3 & -3.0 & 3.3 & 2.28 & 1.80 & 0.71 \\
\hline Opx & 48 & 1035 & 747 & 9.26 & 3.18 & 7.26 & 5.43 & 3.34 & 2.2 & 3.8 & -0.2 & 4.0 & 1.39 & 1.87 & 1.95 \\
\hline Olivine & 25 & 1294 & 791 & 5.09 & 2.90 & 6.70 & 4.89 & 6.67 & -1.6 & 0.2 & -3.8 & 4.0 & 1.64 & 1.16 & 1.49 \\
\hline Olivine & 27 & 1292 & 812 & 4.83 & 2.85 & 6.61 & 4.67 & 6.27 & -1.7 & 0.2 & -3.4 & 3.6 & 1.59 & 1.25 & 1.44 \\
\hline Olivine & 25 & 1286 & 811 & 5.32 & 2.83 & 6.55 & 4.73 & 6.50 & -1.2 & 0.6 & -3.7 & 4.3 & 1.59 & 1.16 & 1.48 \\
\hline Garnets & & & & & & & & & & & & & & & \\
\hline Fe. 16 & 19 & 1713 & 927 & 4.71 & 2.70 & 7.89 & 6.84 & 4.89 & -3.1 & -2.1 & -2.2 & 0.1 & 1.85 & 1.05 & 1.38 \\
\hline $\mathrm{Fe} .36$ & 19 & 1682 & 922 & 4.71 & 2.67 & 7.42 & 5.98 & 5.05 & -2.7 & -1.3 & -2.4 & 1.1 & 1.82 & 1.01 & 1.37 \\
\hline Fe. 54 & 24 & 1736 & 955 & 5.38 & 2.52 & 6.79 & 5.52 & 4.81 & -1.3 & -0.1 & -2.3 & 2.2 & 1.82 & 1.28 & 1.37 \\
\hline $\mathrm{MgAl}_{2} \mathrm{O}_{4}$ & 21 & 1969 & 1080 & 4.85 & 0.92 & 5.47 & 3.84 & 4.19 & -0.6 & 1.0 & -3.3 & 4.3 & 1.82 & 1.40 & 0.67 \\
\hline $\mathrm{SrTiO}_{3}$ & 25 & 1741 & 1168 & 5.67 & 3.92 & 11.2 & 8.77 & 8.70 & -5.3 & -3.1 & -4.8 & 1.7 & 1.49 & 1.63 & 1.96 \\
\hline $\mathrm{KMgF}_{3}$ & 60 & 751 & 488 & 4.87 & 2.98 & 5.02 & 3.46 & 4.72 & -0.0 & 1.4 & -1.7 & 3.1 & 1.54 & 1.60 & 1.50 \\
\hline $\mathrm{RbMnF}{ }_{3}$ & 57 & 675 & 341 & 4.80 & 3.69 & 4.48 & 3.01 & 5.04 & 0.4 & 1.8 & -1.4 & 3.1 & 1.98 & 1.49 & 1.80 \\
\hline $\mathrm{RbCdF}_{3}$ & 40 & 614 & 257 & 1.09 & 2.15 & 4.12 & 3.06 & 3.27 & -3.0 & -2.0 & -1.1 & -0.8 & 2.39 & 1.06 & 0.80 \\
\hline $\mathrm{TlCdF}{ }_{3}^{-1}$ & 49 & 609 & 228 & 7,43 & 0.95 & 5.09 & 3.86 & 3.14 & 2.4 & 3.6 & -2.2 & 5.8 & 2.68 & 1.24 & 1.03 \\
\hline $\mathrm{ZnO}$ & 15 & 1394 & 442 & 4.76 & -2.2 & 9.60 & 6.22 & 3.02 & -4.8 & -1.5 & -5.2 & 3.7 & 3.15 & 0.81 & -0.40 \\
\hline $\mathrm{BeO}$ & 18 & 2201 & 1618 & 5.48 & 1.19 & 5.17 & 3.08 & 4.19 & 0.3 & 2.4 & -3.0 & 5.4 & 1.36 & 1.27 & 0.79 \\
\hline $\mathrm{SiO}_{2}$ & 35 & 378 & 445 & 6.37 & 0.35 & 3.28 & 2.43 & -0.3 & 3.1 & 3.9 & 0.7 & 3.3 & 0.85 & 0.67 & 0.40 \\
\hline $\mathrm{CaCO}_{3}$ & 17 & 747 & 318 & 5.36 & -3.5 & 24.0 & 23.1 & 18.5 & -19 & -18 & -22 & 4.2 & 2.35 & 0.56 & -1.00 \\
\hline
\end{tabular}

tures, and rock salt oxides have similar means, $\mathrm{Al}_{2} \mathrm{O}_{3}$ is high, and fluorites are low. $\{G\}_{V}$ is also relatively constant, with $\mathrm{CsCl}$ structures and fluorites being particularly low. The clustering of properties for crystals having the same cations suggests that composition exerts an important control on the anharmonic properties. The variation of the $\{$ DLA $\}$ parameters with cation radius suggests that a phase change that involves a change of coordination, with a concomitant change in ionic radius, may have a larger effect on the DLA parameters than a coordination conserving phase change, such as $\alpha \rightarrow \beta$. For the same reason we expect $\mathrm{Al}_{2} \mathrm{MgO}_{4}$-spinel to differ from
$\mathrm{Mg}_{2} \mathrm{SiO}_{4}$-spinel because of the disparity of ionic radii in these structures ( ${ }^{\text {iv }} \mathrm{Mg}, 0.49 ;{ }^{\text {vi }} \mathrm{Al}, 0.53 ;{ }^{\text {vi }} \mathrm{Mg}, 0.72 ;{ }^{\text {iv }} \mathrm{Si}, 0.26 \AA$ ).

The shear properties of solids seem to be strongly influenced by the constituent ions. For example, the normalized rigidity $G / K_{S}$ is remarkably constant for $\mathrm{MgO} ; \mathrm{CaO}$; and $\mathrm{Al}_{2} \mathrm{O}_{3}$-rich oxides and silicates but decreases rapidly with $\mathrm{FeO}$ content, regardless of crystal structure. The $\{G\}_{T}$ parameters are similar for all silicates $(2.8 \pm 8 \%, n=8)$.

Generally speaking, the range of the DLA parameters is small, particularly for the limited variation in cation radii exhibited by the important rock-forming oxides and silicates. 
TABLE 2. Dimensionless Logarithmic Anharmonic Derivatives

\begin{tabular}{lccccrc}
\hline \multicolumn{1}{c}{ Averages } & $\left\{K_{S}\right\}_{T}$ & $\{G\}_{T}$ & $\left\{K_{S}\right\}_{P}$ & $\{G\}_{P}$ & $\left\{K_{S}\right\}_{V}$ & $\{G\}_{V}$ \\
\hline Halides & 5.1 & 2.6 & 4.1 & 5.9 & 0.9 & -3.3 \\
Perovskites & 4.8 & 2.7 & 4.4 & 5.0 & 0.3 & -2.2 \\
Garnets & 4.9 & 2.6 & 6.1 & 4.9 & -1.2 & -2.3 \\
Fluorites & 5.0 & 2.2 & 4.8 & 5.2 & 0.2 & -2.9 \\
Oxides & 5.3 & 2.0 & 5.7 & 5.8 & -0.4 & -3.7 \\
Silicates & 5.6 & 2.8 & 5.4 & 5.4 & 0.2 & -2.6 \\
Grand & 5.1 & 2.5 & 5.0 & 5.7 & 0.1 & -3.2 \\
& $( \pm 1.0)$ & $( \pm 1.3)$ & $( \pm 1.9)$ & $( \pm 1.9)$ & $( \pm 1.9)$ & $( \pm 1.9)$ \\
Olivine & 5.1 & 2.9 & 4.9 & 6.7 & 0.2 & -3.8 \\
Olivine & 4.8 & 2.9 & 4.7 & 6.3 & 0.2 & -3.4 \\
MgAl $\mathrm{O}_{4}$-spinel & 4.9 & 0.9 & 3.8 & 4.2 & -0.6 & +1.0 \\
$\beta$ DW & 4.3 & 1.4 & 5.6 & 5.9 & -1.3 & -4.5 \\
$\beta$ BW & 4.8 & 2.7 & 4.2 & 9.7 & 0.6 & -7.0 \\
\hline
\end{tabular}

$\{M\}=\partial \ln M / \partial \ln \rho$.

The number of oxides which has been fully characterized is limited, and it is difficult to discern the roles of chemistry and crystal structure, particularly since the accuracy of the measurements is limited by the low compressibility and thermal expansion of oxides. The data set can be extended considerably by treating the oxides and halides together, and by so doing, we can separate the effects of chemistry and crystal structure. The general behavior of the anharmonic properties can be summarized as follows:

Most of the variation of the bulk modulus with temperature and pressure is due to the change in density. The intrinsic temperature or pressure effect at constant volume is small and may depend on crystal structure. The change of rigidity with density at constant temperature is much less than at constant pressure. The variation of $K_{T}$ and $G$ with density at constant pressure is comparable, but $G$ at constant $T$ is much less sensitive than $K_{S}$ or $K_{T}$ to variations in density. Therefore, to first order, the bulk modulus is a function of volume alone. On the other hand, the variation of $G$ with temperature at constant volume is almost the same as the normalized variation with $T$ at constant $P$, indicating that volume changes are a second-order effect for the rigidity. Materials with transition element cations tend to have low $\{G\}_{T}$ and high $\{K\}_{P}$.

Since the renormalized logarithmetic derivatives are more constant from material to material and show less variation from one crystal structure to another than the unnormalized, or partially normalized $(\partial \ln M / \partial T)_{P}$, derivatives, we suggest that at least some of them are also relatively invariant with temperature, especially at high $T$ and through phase changes. We propose that variations with temperature and phase follow the variations with $K_{S} / G$, ionic radius, and $\gamma$ from compound to compound. The $\{$ DLA $\}$ parameters cannot all be the same function of temperature. The close relationship between $\left\{K_{T}\right\}_{T},\{G\}_{T}$, and $\gamma$ suggests that the former two might be weak functions of temperature from somewhat below $\theta$ to high temperature. Following Grüneisen [1926], we also suggest that $\left\{K_{s}\right\}_{s}$ and, possibly, $\{G\}_{s}$ are independent of temperature since constant entropy implies constant $T / \theta$ in the quasi-harmonic approximation.

The hypothesis that the $\{D L A\}$ parameters depend mainly on composition is supported by the fact that the properties of $\mathrm{MgSiO}_{3}$ and $\mathrm{Al}_{2} \mathrm{O}_{3}$ generally bracket the properties of pyrope $\left[3\left(\mathrm{MgSiO}_{3}\right)+\mathrm{Al}_{2} \mathrm{O}_{3}\right]$ and that $\{K\}_{T},\{K\}_{P},\{G\}_{T}$, and $\{K / G\}_{T}$ of olivine $\left(\mathrm{MgO}+\mathrm{MgSiO}_{3}\right)$ are close to or between the properties of $\mathrm{MgSiO}_{3}$ and $\mathrm{MgO}$. Note that the same ions but five different crystal structures are involved. Similarly, the values for $\{K\}_{T},\{M\}_{P}$, and $\{K\}_{V}$ for $\mathrm{KMgF}_{3}$-perovskite are bracketed by the corresponding values for $\mathrm{MgF}_{2}$ and $\mathrm{KF}$. On

TABLE 3. Means (and Standard Deviations) of Various Measures of Temperature Derivatives

\begin{tabular}{lcccccc}
\hline & $\partial K_{S} / \partial T^{*}$ & $\partial \ln K_{S} / \partial T^{\dagger}$ & $\left\{K_{S}\right\}_{P}$ & $\partial G / \partial T^{*}$ & $\partial \ln G / \partial T^{\dagger}$ & $\{G\}_{P}$ \\
\hline Na halides & $0.12(0.05)$ & $4.7(1.6)$ & $3.9(1.0)$ & $0.09(0.04)$ & $6.0(1.1)$ & $4.9(0.5)$ \\
All halides & $0.12(0.07)$ & $4.7(1.4)$ & $4.1(1.4)$ & $0.09(0.07)$ & $6.7(1.4)$ & $5.9(1.6)$ \\
Rs oxides & $0.17(0.03)$ & $1.7(0.9)$ & $4.8(1.8)$ & $0.15(0.06)$ & $2.2(0.6)$ & $6.2(1.2)$ \\
All oxides & $0.21(0.11)$ & $1.4(0.6)$ & $5.7(2.3)$ & $0.13(0.06)$ & $1.4(0.7)$ & $5.8(2.6)$ \\
Silicates & $0.20(0.05)$ & $1.4(0.5)$ & $5.4(0.8)$ & $0.11(0.02)$ & $1.4(0.3)$ & $5.4(1.2)$ \\
Ilmenites & $0.22(0.04)$ & $1.0(0.3)$ & $4.9(1.6)$ & $0.17(0.06)$ & $1.5(0.6)$ & $7.9(4.8)$ \\
Fluorites & $0.23(0.13)$ & $2.8(0.8)$ & $4.8(0.1)$ & $0.10(0.04)$ & $3.1(1.1)$ & $5.2(1.4)$ \\
Average & $0.17(0.10)$ & $3.1(2.0)$ & $5.0(2.0)$ & $0.11(0.06)$ & $4.0(3.1)$ & $5.7(1.9)$ \\
S.D., \% & 59 & 65 & 40 & 55 & 78 & 33 \\
Range, \% & 92 & 370 & 46 & 89 & 379 & 61 \\
Olivine & 0.16 & 1.2 & 4.9 & 0.13 & 1.6 & 6.7 \\
$\beta$ BW & 0.15 & .9 & 4.2 & 0.23 & 2.0 & 9.7 \\
$\beta$ DW & 0.20 & 1.1 & 5.6 & 0.14 & 1.2 & 5.9 \\
& & & & & & \\
\hline
\end{tabular}

S.D., standard deviation.

* Kilobars per degree Kelvin.

†In $10^{-4} \mathrm{~K}^{-1}$. 
TABLE 4. Materials With Anomalous Rigidity Derivatives

\begin{tabular}{lcccc}
\hline & $K_{S} / G$ & $\gamma$ & $\{G\}_{T} /\{G\}_{P}$ & $\left\{K_{s}\right\}_{V}+\{G\}_{V}$ \\
\hline $\mathrm{KF}$ & 1.94 & 1.50 & 0.32 & -2.6 \\
$\mathrm{RbF}$ & 2.20 & 1.43 & 0.27 & -1.9 \\
$\mathrm{RbBr}$ & 2.09 & 1.47 & 0.30 & -3.7 \\
$\mathrm{BaO}$ & 1.96 & 1.56 & 0.25 & -7.8 \\
$\mathrm{AgCl}$ & 5.44 & 2.08 & 0.26 & -9.9 \\
$\mathrm{TiO}_{2}$ & 1.91 & 1.72 & 0.13 & -11 \\
$\mathrm{ZnF}_{2}$ & 2.67 & 0.97 & 0.03 & -8.3 \\
$\mathrm{BaF}_{2}$ & 2.28 & 1.80 & 0.23 & -2.6 \\
$\mathrm{ZnO}_{\mathrm{BeO}}$ & 3.15 & 0.81 & -0.70 & -7.7 \\
$\mathrm{SiO}_{2}$ & 1.36 & 1.27 & 0.28 & -0.6 \\
$\mathrm{MgA} l_{2} \mathrm{O}_{4}$ & 0.85 & 0.67 & -1.10 & +4.7 \\
$\beta \mathrm{DW}$ & 1.82 & 1.40 & 0.22 & -2.3 \\
$\beta \mathrm{BW}$ & 1.53 & 1.30 & $(0.24)$ & $(-5.8)$ \\
$\gamma \mathrm{DW}$ & & & $(0.28)$ & $(-6.4)$ \\
$\gamma \mathrm{BW}$ & 1.55 & 1.35 & $(0.23)$ & $(-6.4)$ \\
SA average & 2.01 & 1.55 & 0.44 & $-7.6)$ \\
Silicates & 1.67 & 1.26 & 0.55 & -3.1 \\
Olivine & 1.59 & 1.25 & 0.45 & -3.8 \\
\hline
\end{tabular}

Values in parentheses are predictions of DW and BW.

${ }^{*}$ Sumino and Anderson [1984].

the other hand the $\{$ DLA $\}$ parameters vary from one perovskite to another. We have already noted that Ti-bearing compounds share similar characteristics, regardless of crystal structure.

\section{AnOmalous Materials}

Materials which exhibit extremes in their temperature or pressure derivatives are generally anomalous in other respects as well. For example, $\mathrm{ZnO}, \mathrm{SiO}_{2}$-quartz, $\mathrm{AgCl}, \mathrm{MgAl}_{2} \mathrm{O}_{4}$, and the rutiles have anomalous $K_{S} / G, \gamma$, or $K V$ values and also have extreme $\{$ DLA $\}$ values. Many of these compounds are open-packed structures or have cation coordinations not typical of upper mantle minerals or have transition element cations. The $\beta$ - and $\gamma$-spinel have interatomic distances, thermal properties, $K_{S} / G$, and coordinations typical of other mantle silicates and should therefore not deviate much from olivine in

TABLE 5. Comparison of Acoustic and Thermal Gammas

\begin{tabular}{lcc}
\hline & Thermal & Acoustic \\
\hline $\mathrm{MgO}$ & 1.52 & 1.41 \\
$\mathrm{CaO}$ & 1.27 & 1.25 \\
$\mathrm{Al}_{2} \mathrm{O}_{3}$ & 1.27 & 1.33 \\
$\mathrm{MgSiO}_{3}$ & 1.87 & 1.95 \\
$\mathrm{Mg}_{2} \mathrm{SiO}_{4}$ & 1.25 & 1.44 \\
& Averages & \\
Grand & 1.54 & 1.37 \\
Rock salt-halides & 1.58 & 1.40 \\
CsCl-structures & 2.24 & 2.33 \\
Rock salt-oxides & 1.52 & 1.26 \\
Perovskites & 1.40 & 1.42 \\
& & \\
$\beta$-spinel & Predictions & \\
DLA & 1.30 & 1.50 \\
DW & 1.30 & 0.80 \\
BW & 1.30 & 1.38 \\
$\gamma$-spinel & & 1.56 \\
DLA & 1.35 & 0.81 \\
DW & 1.35 & 1.39 \\
BW & 1.35 & \\
\hline
\end{tabular}

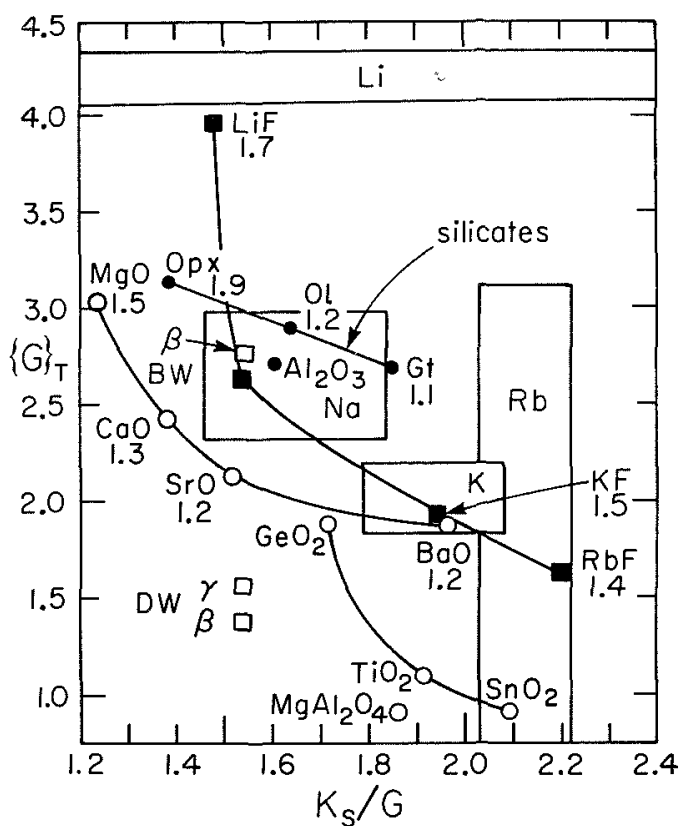

Fig. 2. $\left\{G_{j T}=(\hat{\partial} \ln G / \partial \ln \rho)_{T}\right.$ versus $K_{S} / G$ for oxides, silicates, and halides (Opx, orthopyroxene; Ol, olivine; Gt, garnet). Boxes enclose measurements for $\mathrm{Li}, \mathrm{Na}, \mathrm{K}$, and $\mathrm{Rb}$ rock salt halides. Parameter is $;$ Open squares are DW and BW parameters for $\beta$-spinel. The curves connect the oxide rutiles, rock salt oxides, silicates, and fluorides.

their anharmonic properties. There is no hint of any of the above anomalies in the measured properties of $\beta$ - and $\gamma$-spinel.

Table 4 gives some of the dimensionless parameters for materials which exhibit anomalous behavior of their derivatives.

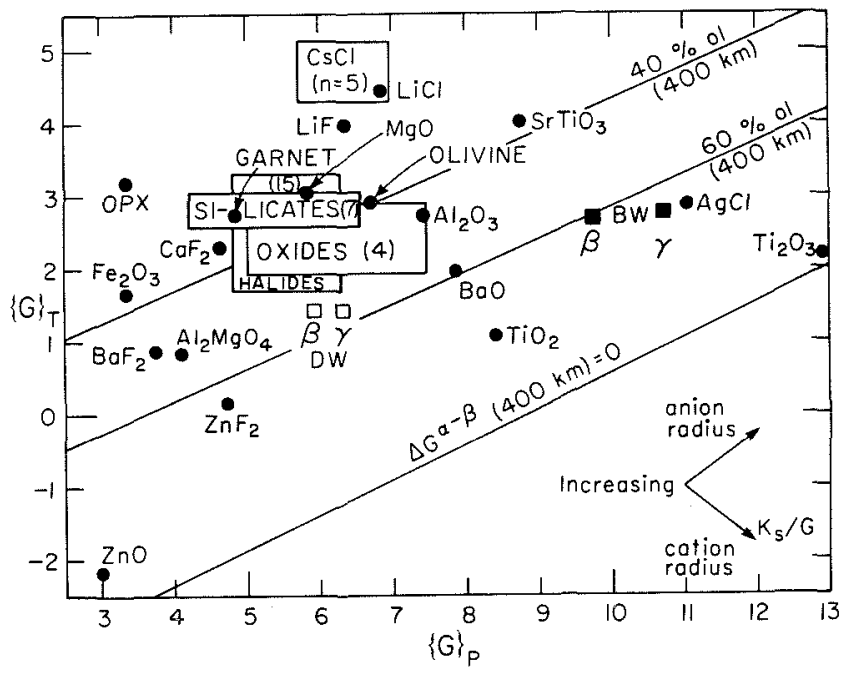

Fig. 3. $\left\{G_{T_{T}}\right.$ versus $\left\{G_{\}_{P}}\right.$ for various crystals. The boxes give averages \pm 1 S.D. for oxides, silicates, and halides ( $n$ is number of samples). The lower diagonal line gives the combination of temperature and pressure derivatives for $\beta$-spinel that give a zero $\Delta G$ (rigidity jump) at $400 \mathrm{~km}$ for the $\alpha-\beta$ transition, assuming a $1400^{\circ} \mathrm{C}$ adiabat. The center diagonal line is the trajectory of $\left\{G_{S_{T}}:\{G\}_{P}\right.$ values for $\beta$-spinel that allows $60 \%$ olivine to be present at $400 \mathrm{~km}$. The squares are the values adopted by DW and BW. Note that their common characteristic is that they both fall near this line, a requirement for an olivine-rich or pyrolite mantle. The upper line passes near olivine and our estimates for $\beta$ - and $\gamma$-spinel. For choices of parameters for $\beta$ spinel along this line the observed size of the $400-\mathrm{km}$ discontinuity implies $40 \%$ olivine. 


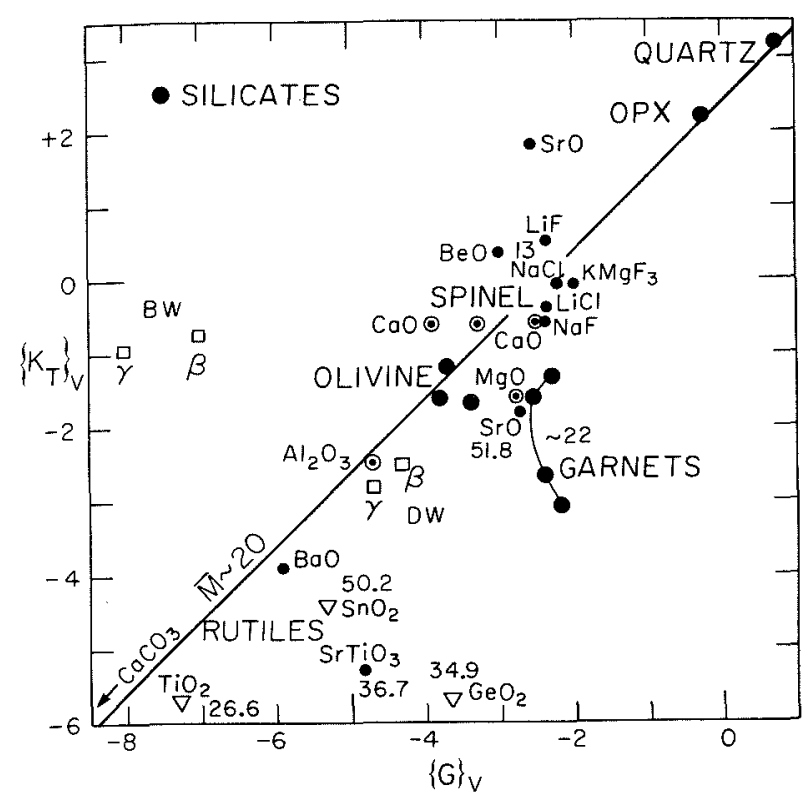

Fig. 4. Intrinsic derivatives $\left\{K_{T}\right\}_{V}$ versus $\{G\}_{V}$. Most oxides and silicates with mean atomic weight $(\bar{M})$ near $20\left(\mathrm{CaCO}_{3}, \mathrm{Al}_{2} \mathrm{O}_{3}, \mathrm{O}\right.$, spinel, Opx, and quartz) fall near the line. Crystals with transition element cations and high $\bar{M}$ fall below the line. The points for $\mathrm{CaO}$ and SrO help to indicate the scatter in presently available data. The open squares are the values adopted by $\mathrm{BW}$ and $\mathrm{DW}$ for the spinel forms of $\mathrm{Mg}_{2} \mathrm{SiO}_{4}$

The most stable parameter $\left\{K_{S}\right\}_{T}$ is nearly constant even for these compounds. The shear derivatives are variable, but $\left\{G_{V}\right.$ and, in particular, $\left\{K_{s}\right\}_{v}-\{G\}_{V}$ are "normal" for most of these compounds. The anomalous behavior of these materials is reflected in anomalous values for $\gamma$ and/or $K_{S} / G$. The latter parameters are available for more materials than are the pressure and temperature derivatives.

Table 4 also shows that oxides, including silicates, on average, are not unusual relative to halides. The use of easily synthesized analogue compounds should therefore provide a good guide to the properties of high-pressure silicate phases. Figures 2 and 5 suggest that the fluorides and chlorides of $\mathrm{Li}$ and $\mathrm{Na}$ are the most pertinent analogues to $\mathrm{Mg} ; \mathrm{Al}$; and Ca-bearing oxides and silicates.

\section{ERRORS}

It is difficult to assign an uncertainty to the measured derivatives. The results of different studies on the same material sometimes differ by $50 \%$. Even in the best cases [e.g., Birch, 1968] the pressure derivatives are likely to be uncertain by $\pm 5 \%$. The uncertainties are much higher for the oxides and silicates which have low compressibility and thermal expansion. Additional uncertainties are introduced by the averaging scheme used to determine isotropic parameters from the single-crystal constants and by uncertainties in $\alpha$. The individual $\{$ DLA $\}$ parameters almost certainly have an error of at least $\pm 10 \%$. For this reason, we form averages of various subsets of the data in our search for systematics. For chemically and structurally similar compounds (e.g., the Na-halides, K-halides, etc.) with high compressibility and thermal expansion we obtain standard deviations of about $\pm 4 \%$ for $\left\{K_{S}\right\}_{T}, \pm 8 \%$ for $\{G\}_{T}$ and $\{G\}_{P}$, and $\pm 22 \%$ for $\left\{K_{S}\right\}_{P}$.

Although some of this variation may be real, these ranges are of the order of uncertainty that we expect for individual measurements, and oxides and silicates, of course, are expected to have much larger errors. We are therefore dealing with very noisy data, and this should be kept in mind as we discuss trends and correlations.

\section{Acoustic $\gamma$}

The acoustic $\gamma$ can be driven from the Debye theory of solids by assuming that the thermal pressure of a solid is caused by the radiation pressure of diffuse elastic waves. It can be written [Anderson, 1987a]

$$
\gamma_{\mathrm{ac}}=\frac{1}{2}\left\{K_{T}\right\}_{T}-\frac{1}{6}-\frac{(K / G)+2}{3(K / G)+4}\left[\left\{K_{T}\right\}_{T}-\{G\}_{T}\right]
$$

The Slater formulation assumes that $\left\{K_{T}\right\}_{T}=\{G\}_{T}$, but this is a very poor approximation. The acoustic $\gamma$ ignores the contribution of the optical modes and is therefore also an approximation to the thermal $\gamma$, but it is generally fairly good for close-packed solids (Table 5). This provides an additional check on the $\{M\}_{T}$ parameters and also suggests that they may be relatively independent of temperature. The BW pressure derivatives for $\beta$ and $\gamma$ give a reasonable $\gamma_{a c}$, but the DW parameters do not. On the other hand, the BW temperature derivatives are anomalous since they imply that the intrinsic temperature derivatives of the rigidity are large relative to $\{K\}_{V}$ and to the extrinsic temperature effect. The ratio $\left\{K_{T}\right\}_{P} /\{G\}_{P}$ for the BW parameters is lower than any other ionic solid except quartz.

It is easy to show that when $\alpha / C_{V}$ is independent of volume

$$
\left\{K_{T}\right\}_{V}=\{\gamma\}_{V}
$$

$\left\{\gamma_{V}\right.$ is generally about $1-1.5$ [Wallace, 1972], and this agrees with values found for $\left\{K_{T}\right\}_{V}$. For $\partial \gamma / \partial T=0$, which is generally valid except for low temperatures,

$$
\left\{K_{T}\right\}_{V}=\{\gamma\}_{T}
$$

$\left\{K_{T}\right\}_{V}$ should therefore increase with temperature to a constant value at high temperature. In the absence of a thermal pressure, $\left\{K_{T}\right\}_{P}=\left\{K_{T}\right\}_{T}$ and $\left\{K_{T}\right\}_{V}=0$. At high temperature, $\{x\}_{v} \sim 0$ and $\left[\left\{K_{S}\right\}_{v}-\left\{K_{T}\right\}_{V}\right] \sim\left(K_{T} / K_{S}\right) \gamma$. This is approximately satisfied by ionic compounds.

We have already pointed out that there is a relation between $\{G\}_{T},\left\{K_{T}\right\}_{T}$, and acoustic $\gamma$. If $\gamma_{\mathrm{ac}}$ has the same temperature behavior as $\gamma$, then the $\left\{M_{T}\right.$ are probably weak functions of temperature, except at low temperature. Acoustic $\gamma$ is generally only slightly dependent on temperatures to somewhat less than $T / 0=1$, even though $C_{V}$ and $\alpha$ are not [Anderson and Suzuki, 1983; Suzuki and Anderson, 1983].

The rigidity parameters should exhibit similar behavior [Wallace, 1972]. In the Earth the effects of temperature and pressure operate in opposing directions, and it is reasonable to assume that the $\{M\}$ are approximately constant throughout at least the upper mantle. In the lower mantle, pressure dominates over temperature, and $\left\{K_{T}\right\}_{V}$ may approach zero. The $\left\{K_{T}\right\}_{T}$ decreases with compression, and therefore $\left\{K_{T}\right\}_{P}$ probably does as well. It is likely that $\{G\}_{V}$ remains important at high pressure [Anderson, 1987a] which means that most of the lateral variation in seismic velocities in the lower mantle is due to variations in $G$. At lower pressures the lateral variations in compressional velocity are due both to $\left\{K_{S}\right\}_{P}$ and $\{G\}_{P}$, and therefore the two isotropic seismic wave velocities have a similar fractional variation except where partial melting is involved.

The $\{M\}_{P}$ parameters are relatively constant at high tem- 


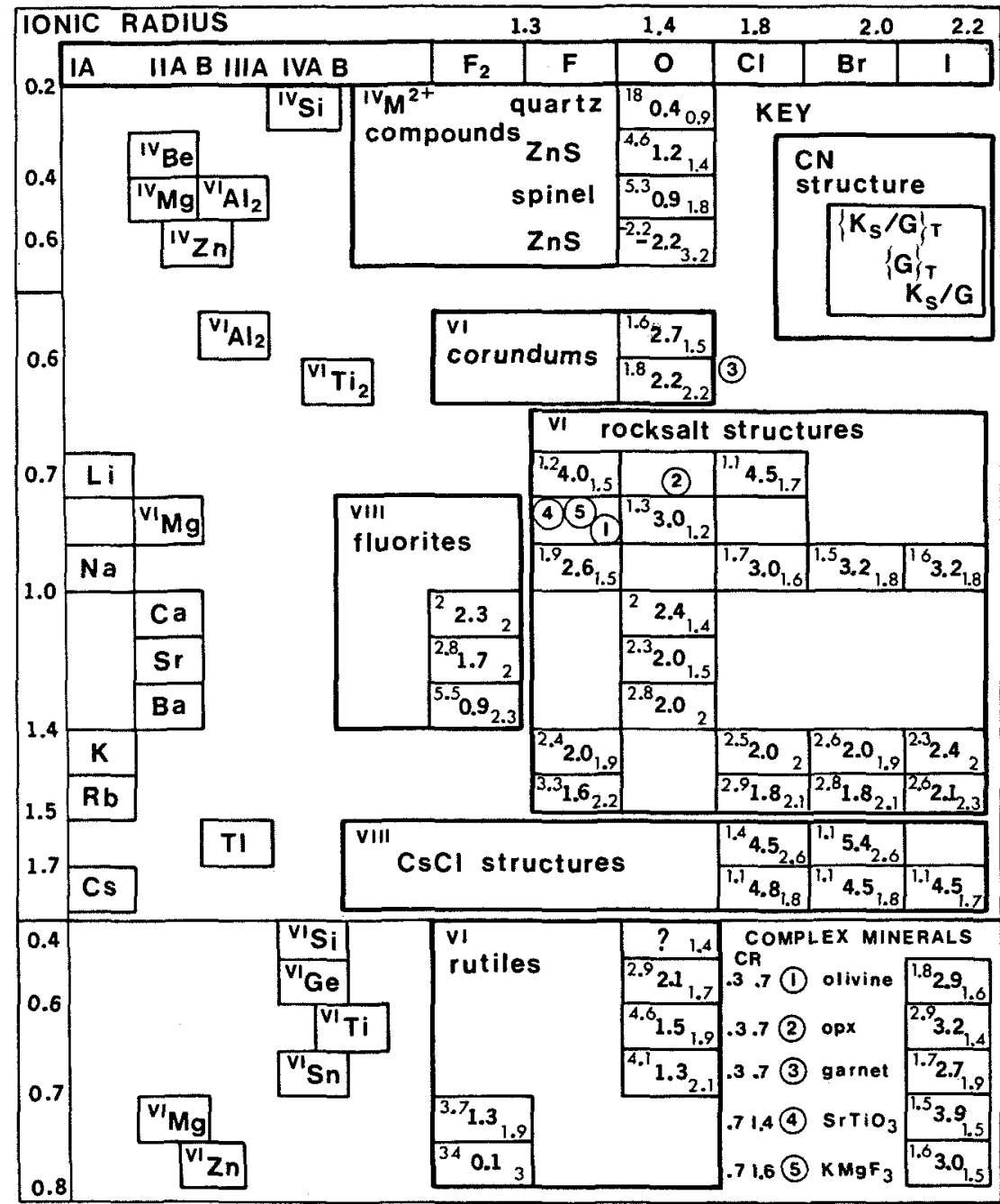

Fig. 5. The shear properties of simple ionic crystals arranged according to anion and cation radius. The circled numbers indicate the approximate location appropriate for the more complex ionic crystals (lower right). Note the trends with cation and anion radius.

perature [Anderson and Suzuki, 1983] particularly for the FeO contents appropriate for mantle minerals. On the other hand, $(\partial \ln M / \partial T)_{P}$ is not independent of temperature or material. There are slight variations of the $\{M\}_{P}$ parameters with temperature when measurements are made over a wide temperature range [Anderson and Suzuki, 1983; Suzuki and Anderson, $1983]$, but the total variation is generally much less than $10 \%$, except at very low $T / \theta$, and examples exist of both increases and decreases with $T$. Since the variation is slight, within experimental error, and since the trend of the change can be negative or positive, we conclude that the assumption of constant $\{M\}_{P}$ is a reasonable one, but variations of $\pm 10 \%$ are also not unreasonable.

The variation of $\gamma$, related to the $\{M\}_{T}$ parameters, is very small, of the order of $4 \%$, and the constancy extends from about $T / \theta=0.5$ to at least 2.5 . Over currently available temperature ranges, $(\partial \ln M / \partial T)_{P}$ is not constant and typically increases about $10-20 \%$. Similarly, $\alpha$ increases with temperature, and this results in nearly constant $\{M\}_{p}$.

\section{Pressure Derivatives}

It is sometimes assumed that the pressure derivatives of silicate spinels are similar to aluminate spinels [e.g., Burdick and Anderson, 1975; Weidner, 1986]. We have shown, however, that crystal structure is a poor guide. Crystals with the rock salt structure, for example, span almost the entire range of measured derivatives. On the other hand, chemically similar compounds of quite different crystal structures have similar anharmonic properties. Therefore the properties of olivine are probably a better guide to the properties of $\beta$ and $\gamma$ than are the properties of spinel. The choice of low $P$ derivatives and normal $T$ derivatives for $\beta$ and $\gamma$ forces the properties of the olivine and spinel phases to converge at high pressure and therefore to decrease the size of the $400-\mathrm{km}$ discontinuity for an olivine-rich mantle. The relationships between the DW parameters violate the systematics displayed by other materials (Figures 2 and 3 and Table 4).

Even if the $P$ - $T$ derivatives of solids were mainly dependent on crystal structure, spinel would not be a good analogue for silicate spinels, which have quite different $K V$ and $K_{S} / G$ values. Nonsilicate spinels have several characteristics not shared by $\beta$ - and $\gamma$-spinel. They have high $K / G$, generally greater than 1.8 , while $\beta$ and $\gamma$ have values of 1.53 , close to olivine. $K V$ of aluminate spinels are much greater than $K V$ for $\beta$ and $\gamma$. The bulk modulus of spinel is higher than $\beta$ and $\gamma$, but $G$ is lower. The ionic radius of ${ }^{\mathrm{iv}} \mathrm{Mg}$ is $0.57 ;{ }^{\mathrm{vi}} \mathrm{Mg}$ is $0.72 \AA$. 
TABLE 6. Trends and Correlations of Dimensionless Logarithmic Anharmonic Parameters

\begin{tabular}{|c|c|c|}
\hline Parameter & $\begin{array}{l}\text { Average } \\
\text { Value }\end{array}$ & Comments \\
\hline$\left\{K_{T}\right\}_{P}$ & 6.8 & $\begin{array}{l}\text { Remarkably oblivious to crystal structure; silicates cluster. Rutiles and crystals with } \\
\text { transition element ions are high. }\end{array}$ \\
\hline$\{G\}_{P}$ & 6 & $\begin{array}{l}\text { Oblivious to crystal structure but not constant; }>\left\{K_{S}\right\}_{P} \text { except for garnets and } \\
\text { rutiles. }\end{array}$ \\
\hline$\left\{K_{S}\right\}_{T}$ & 5 & $\begin{array}{l}\text { Relatively constant; }{ }^{\text {iv }} \mathrm{M}^{2+} \text { compounds low; halides and oxides coherent; opx } \\
\text { anomalous; } \simeq\left\{K_{T}\right\}_{T} .{ }^{*}\end{array}$ \\
\hline$\left\{K_{r}\right\}_{T}$ & 5.3 & $\begin{array}{l}\text { Nearly constant; generally increases with cation radius and molar volume; } \\
\text { independent of crystal structure. }\end{array}$ \\
\hline$\left\{K_{S}\right\}_{P}$ & 5 & $\approx\left\{K_{T P}\right\}_{P}-2$ \\
\hline$\left\{K_{S} / G\right\}_{T}$ & 2.8 & Generally increases with $K_{S} / G$ and cation radius; $C s C l$ structures low. \\
\hline$\{G\}_{T}$ & 2.5 & $\begin{array}{l}\text { Constant for most geophysical compounds, oxides and halides are coherent; } \\
\text { decreases with } K_{S} / G \text { and anion radius. Decreases with cation radius. }\end{array}$ \\
\hline$K_{S} / G$ & 2 & Increases with transition ion content, anion radius, and cation radius. \\
\hline$\left\{K_{S}\right\}_{V}$ & 0.2 & $\begin{array}{l}{ }^{\text {iv }} \mathrm{M}^{2+} \text { compounds anomalous; garnets low; variability due to }\left\{K_{S}\right\}_{P} \text {; increases with } \\
\{G\}_{,} \text {. Quartz and rutiles anomalous. }\end{array}$ \\
\hline$\left\{K_{r}\right\}_{V}$ & -1.5 & $\begin{array}{l}\text { Garnets, fluorites and corundums are more negative than most structures. Decreases } \\
\text { with anion radius. }\end{array}$ \\
\hline$\{G\}_{V}$ & -3.6 & $\begin{array}{l}\text { Oxides somewhat higher than halides; } C s C l \text { structures low. Ti compounds high; } \\
\text { depends on crystal structure; covaries with }\{G\}_{P},\left\{K_{S}\right\}_{V} \text {, and }\left\{K_{T}\right\}_{V} \text {. Increases with } \\
\text { cation radius; decreases with anion radius. }\end{array}$ \\
\hline$\gamma$ & 1.5 & $\begin{array}{l}\text { Oxides and halides coherent. } C s C l \text { structures high. } \mathrm{Zn} \text { compounds low. }{ }^{\text {iv }} \mathrm{M}^{2+} \\
\text { compounds low. Decreases with cation radius; increases with anion radius. }\end{array}$ \\
\hline$\left\{K_{T} / G\right\}_{P}$ & 1.3 & Oxides and halides coherent; $\mathrm{Zn}$, quartz, rutiles, and opx anomalous. \\
\hline$\left\{K_{S}\right\}_{V}-\{G\}_{V}$ & 3.8 & $\begin{array}{l}\text { Garnets and some perovskites and rutiles are anomalous; } O \text { l, Opx, quartz, } \mathrm{MgO} \text {, } \\
\mathrm{Al}_{2} \mathrm{O}_{3}, \mathrm{CaO}, \mathrm{BaO}, \mathrm{MgAl}_{2} \mathrm{O}_{4} \text {, and } \mathrm{TiO}_{2} \text { all have the same value }(\sim 2) \text {. }\end{array}$ \\
\hline$\gamma_{\mathrm{ac}}$ & 1.4 & Increases with $\gamma$; silicates cluster: anomalous for $\mathrm{ZnO}, \mathrm{MgAl}_{2} \mathrm{O}_{4}$, and rutiles. \\
\hline
\end{tabular}

*The comment that oxides and halides are coherent means that the parameters for the oxides are similar to those of the halides of similar ionic radii.

$\mathrm{MgAl}_{2} \mathrm{O}_{4}$ has a low $(\partial G / \partial P)_{T}$ relative to other materials except those with either $\mathrm{M}^{2+}$ ions in four coordination or transition element cations. Although the dimensionless derivative $(\partial \ln G / \partial \ln \rho)_{T}$ is less for spinel than for olivine, the other dimensionless parameters adopted for $\beta$ and $\gamma$ by DW and BW are not spinellike. Weidner and Hamaya [1983] also caution against adopting values of one spinel for another.

DW also uses the low-pressure derivative of the shear velocity of $\mathrm{Fe}_{2} \mathrm{SiO}_{4}$-spinel as justification for a low value for $\mathrm{Mg}_{2} \mathrm{SiO}_{4}$-spinels. However, $G^{\prime}$ is low for transition element compounds. The average $\{G\}_{T}$ for these compounds is 1.4 compared to the grand average of all compounds of 2.5 . The DW value for $\beta$-spinel is 1.4. A direct determination of the shear velocity jump associated with the olivine-spinel transformation in $\mathrm{Fe}_{2} \mathrm{SiO}_{4}$ at high temperature and high pressure gives $14 \%$, about the same as at low pressure and temperature [Fukizawa and Kinoshita, 1982]. This is much greater than the $V_{S}$ jump at $400 \mathrm{~km}$, as also predicted for $\mathrm{Mg}_{2} \mathrm{SiO}_{4}$ by the considerations in this paper.

\section{Temperature Derivatives}

There has been little work done on the formulation of systematics or general principles governing the temperature derivatives of elastic moduli. Table 3 shows that $\partial K_{S} / \partial T$ and $\partial G / \partial T$ show little variation for given groups of crystals and between groups. Numerically, $\partial G / \partial T$ is less than $\partial K_{S} / \partial T$, and both vary by about a factor of 2 . Halides have slightly smaller values than the oxides. The fully normalized derivatives $\left\{M_{P}\right.$ exhibit a smaller range and average variability, and there is more overlap between the halides and oxides.

Bina and Wood [1987] assume that $(\partial \ln M / \partial T)_{P}$ is constant from material to material and, in particular, through the $\alpha-\beta$ phase change. Table 3 shows that these parameters are not nearly as constant as the other forms of the temperature de- rivatives, exhibiting a range of almost $400 \%$ for the intergroup averages. There is therefore no basis for assuming that $\beta$ spinel moduli have abnormally high temperature derivatives, the essential element behind the BW conclusion that olivinerich materials give a small $400-\mathrm{km}$ discontinuity. The parameters assigned by $\mathrm{BW}$ to $\beta$ are also anomalous in other respects (Table 2 and Figures 3 and 4). The temperature derivatives $(\partial M / \partial T)_{P}$ correlate with $\alpha M$, giving nearly constant $\{M\}_{P}$ for a variety of materials.

\section{Prediction of Derivatives of High-Pressure Phases}

We are now in a position to estimate the properties of high-pressure silicates by several methods:

1. We can perturb the properties of chemically similar compounds by using correlations with ionic radius, radius ratios, $K_{S} / G$, and $\gamma$.

2. We can perturb the properties of isostructural compounds by replacing the unwanted ions by the desired ions using the above correlations.

3. We can interpolate in parameter tables such as Table 1 or Figure 5.

The task is somewhat subjective since the various criteria sometimes give conflicting results. We therefore estimate the individual anharmonic properties and various combinations such as $\{M\}_{V},\{K / G\}_{T},\{K\}_{V}-\{G\}_{V}$, etc. by all of the above techniques and then iterate to a self-consistent solution.

The anharmonic properties of some high-pressure phases of olivine and orthopyroxene are predicted from their systematic variation with each other and with known properties such as $\gamma, K_{S} / G$, and ionic radii. The results are given in Table 7 . Crystal structure itself is a secondary consideration, but note the similarity between the properties of garnet and majorite 
TABLE 7. Anharmonic Parameters for Oxides and Silicates and Predicated Values for Some High-Pressure Phases

\begin{tabular}{llcccccc}
\hline & $\left\{K_{T}\right\}_{T}$ & $\left\{K_{S}\right\}_{T}$ & $\{G\}_{T}$ & $\left\{K_{T}\right\}_{P}$ & $\left\{K_{S}\right\}_{P}$ & $\{G\}_{P}$ \\
\hline$\alpha$ & olivine & 5.0 & 4.8 & 2.9 & 6.6 & 4.7 & 6.5 \\
$\beta$ & spinel* & 4.9 & 4.8 & 3.0 & 6.6 & 4.7 & 6.4 \\
$\gamma$ & spinel* $^{*}$ & 5.1 & 5.0 & 3.1 & 6.8 & 4.9 & 6.5 \\
& garnet $^{*}$ & 4.8 & 4.7 & 2.7 & 7.9 & 6.8 & 4.9 \\
$\mathrm{MgSiO}_{3}$ & majorite* & 4.9 & 4.7 & 2.6 & 7.9 & 6.0 & 4.5 \\
$\mathrm{Al}_{2} \mathrm{O}_{3}$ & ilmenite & 4.4 & 4.3 & 2.7 & 6.8 & 4.3 & 7.5 \\
$\mathrm{MgSiO}_{3}$ & ilmenite* & 4.7 & 4.5 & 2.7 & 7.0 & 4.3 & 6.0 \\
$\mathrm{MgSiO}_{3}$ & perovskite* & 4.5 & 4.5 & 3.5 & 7.5 & 5.5 & 6.5 \\
& perovskite* & 4.2 & 4.1 & 2.8 & 6.2 & 4.0 & 5.7 \\
$\mathrm{SiO}_{2}$ & stishovite* & 4.5 & 4.4 & 2.4 & 7.5 & 6.4 & 5.0 \\
\hline
\end{tabular}

*Predicted.

and $\mathrm{MgSiO}_{3}$-ilmenite and corundum (corundums and ilmenites have similar structures). On the other hand, $\beta$ - and $\gamma$ spinel have properties similar to olivine, a different structure. Majorite and $\mathrm{MgSiO}_{3}$-ilmenite differ from garnet and $\mathrm{Al}_{2} \mathrm{O}_{3}$, respectively, by the substitution of ${ }^{\mathrm{v}}[\mathrm{MgSi}]$ for ${ }^{\mathrm{vi}} \mathrm{Al}_{2}$, and these groups have similar ionic radii and elastic properties. On the other hand, the transformation of $\mathrm{Al}_{2} \mathrm{MgO}_{4}$-spinel to $\mathrm{Mg}_{2} \mathrm{SiO}_{4}$-spinel involves the substitution of vi $\mathrm{Mg}_{2}{ }^{\mathrm{iv}} \mathrm{Si}$ for ${ }^{\text {vi }} \mathrm{Al}_{2}$ ${ }^{i v} \mathrm{Mg}$, groups which have dissimilar properties. $\mathrm{Mg}_{2} \mathrm{SiO}_{4}$-spinels are closer to olivine in $\gamma, K_{S} / G$, ionic radii, and radius ratio of the cations than to $\mathrm{Al}_{2} \mathrm{MgO}_{4}$-spinel.

A check on the pressure derivatives of the spinel forms of olivine can be obtained as follows. The thermal $\gamma$ is approximately [Anderson, 1987a]

$$
\gamma=\frac{1}{2}\{G\}_{T}-\frac{1}{6}
$$

Using this relation, we derive values for $\{G\}_{T}$ of 2.9 for $\beta$ spinel and 3.0 for $\gamma$-spinel, in excellent agreement with values estimated above. By contrast, the DW values for $\{G\}_{T}$ are 1.4 for both $\beta$ and $\gamma$ and the BW values are about 2.7. As a check, we calculate 2.83 for $\alpha-\mathrm{Mg}_{2} \mathrm{SiO}_{4}$, which is in excellent agreement with the measured $\{G\}_{T}$ for olivine.

In order to utilize these predicted values in estimating elastic properties of the mantle we need to know $\alpha(T)$, to calculate the variation of the extrinsic and intrinsic derivatives at $P=0$ and at high temperature, and an equation of state, to calculate $\rho, K_{S}$, and $G$ at the desired pressure. In the absence of information to the contrary one can assume that some of the DLA parameters are independent of $T$ which results in the corresponding unnormalized pressure and temperature derivatives being a function of temperature. For example, if $\{M\}_{T}$ is constant, $(\partial M / \partial P)_{T}$ is proportional to $M(T) / K_{T}(T)$, and if $\{M\}_{P}$ is constant, $(\partial M / \partial T)_{P}$ varies as $\alpha(T) M(T)$. Once $\rho(T), M(T)$, $\partial M / \partial P$, and $\partial M / \partial T$ are determined at the temperature of interest, the finite strain equations [Sammis et al., 1970] can be used in the manner described by Burdick and Anderson [1975], either along an isotherm or an adiabat. The $\left\{K_{S}\right\}$ and $\left\{K_{T}\right\}$ parameters cannot all be independent of temperature since $K_{S}=K_{T}(1+\alpha \gamma T)$. For a quasi-harmonic solid, $\left\{K_{S}\right\}_{S}$ should be relatively constant. If $\{G\}_{S}$ and $\{M\}_{X}(X=P, T$, or $V)$ are assumed to be constant, then the temperature dependence of the other \{DLA\} parameters can be computed.

\section{Application to the Mantle}

Finite strain equations of state are available to extrapolate the elastic properties of minerals to high pressure, given the low-pressure elastic moduli and their derivatives [Birch, 1939;
Sammis et al., 1970; Burdick and Anderson, 1975]. These are based on the expansion of the strain energy in terms of strain invariants and are consistent with classical elasticity theory [Birch, 1978]. Equations based on expansions in pressure [e.g., Weidner, 1986] have no theoretical basis and are approximations valid only at very low pressure. The Murnaghan equation falls in this category. As we show in the next section, the assumption that $\left\{K_{T}\right\}_{T}$ is independent of $P$ leads to the Murnaghan equation of state for $K_{T}$, but the other moduli are not linear functions of $P$.

Given an equation of state in terms of strain or density, it remains to estimate the moduli and their derivatives at high temperature and $P=0$ to initiate the calculation along an adiabat or isotherm. The \{\}$_{P}$ parameters (e.g., $(\partial \ln G / \partial \ln$ $\rho)_{P}$ ) give the change in modulus for a given change in density at constant $P$. The latter can be calculated from $\alpha(T)$ as

$$
-(\partial \rho / \rho)_{P}=\alpha(T) d T
$$

The assumption that $\{M\}_{T}$ and $\{M\}_{P}$ are independent of $T$ gives $\partial M / \partial T$ and $\partial M / \partial P$ at the temperature of interest. Classical solid state physics shows that $\alpha$ increases rapidly with temperature, a result which has been ignored in some recent studies of mantle mineralogy [e.g., Weidner, 1985, 1986].

The rigidity $G$ of $\beta$-spinel is $43 \%$ greater than that of olivine at room conditions, giving a $\Delta V_{S} / V_{S}$ of $15 \%$ [Weidner, 1986]. $\Delta G / G$ at $1600^{\circ} \mathrm{C}$ is increased to $58 \%$ with the $\mathrm{DW}$ parameters but decreased to $33 \%$ with the BW parameters. At $130 \mathrm{kbar}$, $\Delta G / G$ is reduced to $31 \%$ by $\mathrm{DW}$ and $23 \%$ by $\mathrm{BW}$. The bulk modulus difference is decreased from $35 \%$ at ambient conditions to about $21 \%$ with the DW and BW parameters. These large reductions in the modulus differences between $\alpha$ and $\beta$ are a direct result of the large differences between the derivatives of olivine and $\beta$-spinel adopted by these authors.

At $400 \mathrm{~km}, \delta \rho / \rho$ for $\alpha \rightarrow \beta$ decreases from about $7.8 \%$ at ambient conditions to less than $6 \%$ at the $P$ and $T$. To some extent, this counteracts any decrease in the modulus on the velocities. If the $\Delta G / G$ contrast is nearly the same at $400 \mathrm{~km}$ as it is at ambient conditions, as is approximately the case for the DLA parameters, then $\Delta V_{S} / V_{S}$ can actually be larger at 400 $\mathrm{km}$ than at ambient conditions.

There are a few technical differences between the recent studies. Anderson and Bass [1986] and Bass and Anderson $\lceil 1984]$ use the full third-order finite strain equations with temperature dependent parameters [e.g., Sammis et al., 1970; Burdick and Anderson, 1975]. DW uses a simple linear dependence of the moduli with respect to temperature and pressure rather than thermodynamic equations of state involving strain. He also assumes that the coefficient of thermal expansion is independent of temperature which further reduces the calculated seismic velocities in the spinel region of the mantle. BW do their calculations along an isotherm instead of an adiabat but make an erroneous correction, of the wrong sign, in correcting from adabatic to isothermal derivatives. These technical details do not have much effect on the calculated velocity jumps at $400 \mathrm{~km}$ associated with the olivine-spinel phase change. These are mainly controlled by the differences in the temperature and pressure derivatives between the $\alpha$ and $\beta$ phases. They do, however, affect the mean velocities and velocity gradients in the transition region and the jump in velocity at the spinel-postspinel phase change near $650 \mathrm{~km}$. The low velocities in the transition region, relative to $\beta$ - and $\gamma$-spinel, and the high-velocity gradients, relative to those expected in a homogeneous adiabatically compressed solid with "normal" derivatives, led Anderson and Bass [1986] to propose a rela- 
tively olivine-poor mantle with a high clinopyroxene and garnet content and with a low enough garnet/clinopyroxene ratio so that the Cpx-garnetite transition occurred well below $400 \mathrm{~km}$.

BW assumed that $(\partial \ln M / \partial T)_{P}$ rather than $(\partial M / \partial T)_{P}$ is constant through a phase change; $(\partial M / \partial T)_{P}$ is fairly independent of composition and crystal structure, but $M$ is highly variable. For example, $\partial K_{S} / \partial T$ averages $-0.17( \pm 0.1)$ kbar $\mathrm{K}^{-1}$ for alkali halides, rock salt oxides, perovskites, olivine, and $\mathrm{Al}_{2} \mathrm{O}_{3}$. On the other hand, for the same materials, $\partial$ in $K_{\mathrm{S}} / \partial T$ is $-4.6( \pm 1.6),-1.5( \pm 0.9),-1.9( \pm 0.4),-1.2$, and -0.7 . For a variety of compounds, $\partial G / \partial T$ is $-0.13( \pm 0.08)$, but $(\hat{O} \ln G / \partial T)_{P}$ is $-3.2( \pm 2.8)$. Halides are $-6.4( \pm 1.6)$, while rock salt oxides are $-2.4( \pm 1.2)$. By assuming that $(\partial \ln$ $M / \partial T)_{P}$ is the same for olivine and $\beta$-spinel, BW effectively assumed a large $(\partial M / \partial T)_{P}$ for the spinel structure which means that the properties of olivine and spinel converge at high temperature. Both $\partial M / \partial T$ and $\partial \ln M / \partial T$ are, of course, relatively constant when comparing materials with similar $M$.

The apparent agreement between the results of BW and DW is entirely illusory. Most of the convergence between the properties of olivine and spinel is accomplished by BW at high temperature, while DW forces the convergence at high pressure by his choice of pressure derivatives. The difference $\Delta G$ of the rigidity of $\alpha$ and $\beta$ is $340 \mathrm{kbar}$ at normal conditions. At $1600^{\circ} \mathrm{C}$ it is $335 \mathrm{kbar}$ with DW but only 191 with BW parameters. The reduction with pressure is $113 \mathrm{kbar}$ for DW and only $2 \mathrm{kbar}$ for BW. By interchanging the DW and BW $T$ and $P$ derivatives we can obtain $\Delta G$ of $78-333 \mathrm{kbar}$ or $\Delta G / G$ at $410 \mathrm{~km}$ for $10-42 \%$. Both DW and BW conclude that about $60-75 \%$ olivine is consistent with the size of the $400-\mathrm{km}$ discontinuity, but it is clear that this is entirely a result of their ad hoc adjustments of the derivatives for $\beta$. Almost any amount of olivine could be rationalized by this procedure. They also both ignore the orthopyroxene-majorite contribution to the increase of velocity near $400 \mathrm{~km}$. DW assumes that this transition occurs much deeper. Irifune and Ringwood [1987] show that the orthopyroxene-majorite transformation is complete by $400-450 \mathrm{~km}$, whereas DW has an appreciable orthopyroxene content to $500 \mathrm{~km}$, thereby considerably decreasing the velocities in the upper part of the transition region.

\section{Equation of State}

The DLA parameters are nearly constant from material to material but have small, systematic variations with chemistry. They are not constant for a given crystal structure but are more so than other forms of the derivatives. For a given cation or cation radius, however, the parameters are almost constant. We therefore suspect that the normalized derivatives are relatively constant through coordination-conserving phase changes in close-packed structures. The effects of coordination changes can be estimated from changes in ionic radius, $K / G$ and $\gamma$ and from properties of the component oxides. As an extension of this idea one can assume that the DLA parameters are relatively constant with temperature and pressure. This gives $(\partial M / \partial P)_{T}$ and $(\partial M / \partial T)_{P}$ that are constant or increase with $T$ and are constant or decrease with $P$, consistent with available data.

The assumption that the DLA parameters are independent of $T$ and $P$ leads directly to the following equations of state:

$$
\frac{M(P)}{M(P=0)}=\left[\frac{K_{T}(P=0)+\left\{K_{T}\right\}_{T} P}{K_{T}(P=0)}\right]^{(M)_{T} /\left(K_{T}\right) T}
$$

$$
\frac{M(T)}{M\left(T_{0}\right)}=-\exp \int_{0}^{T}\{M\}_{P} \alpha(T) d T
$$

For $K_{T}$ the first equation is equivalent to the EmdenMurnaghan equation of state. Since $\left\{K_{T}\right\}_{T}>\{M\}_{T}\left(M \neq K_{T}\right)$, $M$ increases with pressure as a fractional power of $P$. Since $\alpha(T)$ increases rapidly with $T, M(T)$ decreases rapidly with temperature. If $\{M\}_{P}$ is independent of $T, \partial M / \partial T$ increases with $T$. For high pressure it is preferable to use the finite strain equations instead of the above expansion in terms of pressure.

DW assumes that $G$, as well as $K_{S}$, increases linearly with pressure, whereas the above equations show that $G$ increases as a fractional power of pressure if $\left\{K_{T}\right\}_{T}$ and $\{G\}_{T}$ are both independent of pressure. This effect is counteracted by his choice of a low $\partial G / \partial P$ for $\beta$-spinel. Since DW assumes that the majority of the orthopyroxene content of pyrolite, as well as the garnet and clinopyroxene contents, remain untransformed until $500 \mathrm{~km}$ or greater depths, only about $60 \%$ of his mantle experiences a phase change near $400 \mathrm{~km}$. The large orthopyroxene and clinopyroxene contents below $400 \mathrm{~km}$, in his model, considerably reduces the velocity jump near $400 \mathrm{~km}$.

\section{Discussion}

From the results of this study we can formulate the following general rules regarding the behavior of dimensionless anharmonic properties:

1. Normalized temperature and pressure derivatives depend more on the nature of the cations than on crystal structure

2. Oxides and halides behave in a similar fashion and have properties which depend primarily on cation radius.

3. $\left\{K_{T}\right\}_{T}$ and $\left\{K_{S}\right\}_{T}$ are nearly independent of both composition and crystal structure.

4. $\left\{K_{S} / G\right\}_{T}$ increases with $K_{S} / G$ and, for rutiles and rock salt structures, with cation radius.

5. $\{G\}_{P}$ is generally close to $\left\{K_{T}\right\}_{P}$.

6. $\{G\}_{V}$ is negative, becoming less so as $\{G\}_{T}$ increases

7. $\{G\}_{T}$ is nearly constant for iron-free (transition ion-free) silicates and important rock-forming oxides $\left(\mathrm{MgO}, \mathrm{Al}_{2} \mathrm{O}_{3}\right)$. It is slightly less for large-ion oxides $(\mathrm{CaO}, \mathrm{BaO}, \mathrm{SrO})$. It varies by more than a factor of 2 for a given crystal structure.

8. The properties of ${ }^{\text {iv }} \mathrm{MgAl}_{2} \mathrm{O}_{4}$ are closer to ${ }^{\text {iv }} \mathrm{BeO}$ than to $\mathrm{Al}_{2} \mathrm{O}_{3}$, suggesting that the small iv $\mathrm{Mg}$ ion and its tetrahedral coordination dominate the anharmonic properties. For this and other reasons the aluminate spinels are not good elastic analogues for silicate spinels.

9. $\left\{K_{s}\right\}_{V}$ is nearly zero for materials of geophysical interest.

10. Material with anomalous $\{$ DLA $\}$ parameters is generally anomalous in other parameters such as $\gamma$ and $K_{S} / G$. There is no reason to attribute anomalous properties to $\beta$ - or $\gamma$ spinel.

11. $\left\{K_{S}\right\}_{V}$ and $\left\{K_{T}\right\}_{V}$ increase with $\{G\}_{V}$. Olivine, orthopyroxene, $\mathrm{MgO}, \mathrm{Al}_{2} \mathrm{O}_{3}, \mathrm{SiO}_{2}$-quartz, $\mathrm{CaCO}_{3}, \mathrm{CaO}, \mathrm{BaO}$, $\mathrm{MgAl}_{2} \mathrm{O}_{4}, \mathrm{KMgF}_{3}$, and $\mathrm{TiO}_{2}$ all satisfy the same $\{K\}_{V}$ $-\{G\}_{V}$ relation. Crystals containing transition elements or high-coordination cations such as garnets, some rutiles, $\mathrm{CsCls,}$ fluorites, and perovskites have less negative $\{G\}_{V}$ for a given $\left\{K_{r}\right\}$ r

One would not expect open-packed structures such as quartz to satisfy the same systematics as the more closepacked structures. On the other hand, one can use anomalies in such parameters as $\gamma$ and $\mathrm{K}_{\mathrm{S}} / G$ to identify materials that 
may have anomalous temperature and pressure behavior. For example, quartz has values for $\gamma$ and $K_{S} / G$ which are about half the typical values and is equally low in $\left\{K_{T}\right\}_{T}$ and $\left\{K_{T}\right\}_{P}$ and very low in $\{G\}_{P}$ and $\{G\}_{T}$. Nevertheless, it has a "normal" $\left\{K_{S}\right\}_{V}-\{G\}_{V}$. Orthopyroxene has anomalous $\gamma$, $\left\{K_{T}\right\}_{T}$, and $\{G\}_{P}$ but also has normal $\left\{K_{S}\right\}_{V}-\{G\}_{V}$.

The intrinsic derivatives $\left\{K_{S}\right\}_{V}$ and $\{G\}_{V}$ are relatively constant and covarient. Although $\mathrm{Opx}, \mathrm{TiO}_{2}$, and $\mathrm{MgAl}_{2} \mathrm{O}_{4}$-spinel appear to be anomalous in some of their individual derivatives they fall on the same trend line as olivine, $\mathrm{MgO}, \mathrm{Al}_{2} \mathrm{O}_{3}$, and most other iron-free (transition ionfree) materials. The minerals with cations most relevant to mantle materials (olivine, spinel, $\mathrm{MgO}, \mathrm{Al}_{2} \mathrm{O}_{3}$ ) have similar intrinsic derivatives, and even anomalous materials such as Opx and $\mathrm{TiO}_{2}$ have similar $\left\{K_{S}\right\}_{V}-\{G\}_{V}$ values. In our estimates of the derivatives of unmeasured phases we take advantage of these robust features as well as correlations between these parameters and with $\gamma$ and $K / G$.

In several cases we have measurements or estimates of the elastic properties, $\gamma$, or $K_{S} / G$ but no information regarding the pressure or temperature derivatives. In the simple halides and oxides there is a general correlation between the elastic properties, $\gamma$, and $K_{S} / G$ and between these parameters and $K_{S}^{\prime} / G^{\prime},\left\{G_{V},\{G\}_{T}\right.$, and $\left\{K_{S}\right\}_{T}$. For example, $K_{S}, G$, and $G / K_{S}$ decrease as one increases the cation radius in the alkali halide and oxide rock salt structures. In general, $\gamma$ also decreases. $\left\{G_{\}_{V}}\right.$ generally becomes more negative, $\left\{G_{\}_{T}}\right.$ decreases, and $\left\{K_{S}\right\}_{T}$ increases.

Olivine and $\beta$-spinel have similar thermal $\gamma, K_{S} / G$, and interatomic distances. They also involve the same coordination and, of course, the same ions. They are both orthorhombic crystals. The main difference is that olivine is based on a hexagonal closest-packed (hcp) sublattice of oxygen ions while spinel is based on a cubic close-packed (fcc) sublattice. There is no substantial systematic difference in the $\{\mathrm{DLA}\}$ parameters for fcc lattices (rock salts, MgO) and hcp lattices (corundum).

\section{Conclusions}

The temperature and pressure derivatives of ionic crystals, when recast into the form of dimensionless volume and intrinsic derivatives, are well behaved and show little variability. The parameters are controlled by interatomic forces and ionic distances rather than by crystal structure. Therefore isochemical compounds rather than isostructural compounds are the better guide to the expected properties of unmeasured materials. On this basis the properties of $\beta$ - and $\gamma$-spinel should be similar to the properties of olivine. There is no evidence that their properties should be unusual as assumed by Weidner [1986] and Bina and Wood [1986]. These authors considerably underestimated the size of the velocity jump at $400 \mathrm{~km}$ associated with the $\alpha-\beta$ phase change. The orthopyroxene-majorite transformation also causes a large increase in the compressional velocity between 350 and $400 \mathrm{~km}$ which compounds the problem for a peridotite or pyrolite mantle. This suggests that clinopyroxene and garnet are important constituents of the mantle near $400 \mathrm{~km}$ and probably in the transition region as well. Their presence will decrease the size of the velocity increase between 350 and $400 \mathrm{~km}$ and increase the velocity gradient in the transition region. In order to match the velocity increase near $400 \mathrm{~km}$ the olivine plus orthopyroxene content of the mantle must be less than $50 \%$ by volume unless there is a change in chemistry near $400 \mathrm{~km}$.
In this case the mantle above $400 \mathrm{~km}$ can be peridotite or pyrolite, but there must be considerably less olivine below 400 $\mathrm{km}$. In either case the transition region would be richer in a basaltic component than in peridotite or pyrolite. Piclogite [Anderson and Bass, 1986], with a composition between lherzolite and eclogite, has the appropriate mineralogy to explain the seismic properties and to be the source region for basalts and komatiites.

Compared to the values for most minerals and those used by $\mathrm{DW}$, the value adopted by $\mathrm{BW}$ for the temperature derivative of $G$ of the $\beta$ phase is extremely high. On the other hand, DW adopts extremely low-pressure derivatives for $G$ and $K$ and high-temperature derivatives for $K$. The net result is that the values computed for the moduli of $\beta$-spinel by DW and BW diverge with increasing temperature or increasing pressure. This calls into question the claimed robustness of their solutions and the conclusion that a homogeneous peridotitic composition is a satisfactory fit to the seismic velocity profiles near $400 \mathrm{~km}$ and below.

Most peridotites contain more than $80 \%$ olivine plus orthopyroxene. Pyrolite is a hypothetical rock of rather flexible composition, but its various versions always contain more than $53 \%$ olivine and more than $70 \%$ olivine plus orthopyroxene. Piclogite is also a hypothetical rock with proportions of minerals based on seismic velocities in the transition region. We can define it to be intermediate in composition to picrite and harzburzite, or lherzolite, and to have less than $50 \%$ olivine plus orthopyroxene in order to distinguish it from pyrolite. Clinopyroxene and, depending on pressure, spinel or garnet are the dominant phases. Natural rocks having these compositions would be called olivine eclogites, garnet pyroxenites, or peridotitic komatiites. In seismic modeling, the amount of olivine and orthopyroxene is constrained by the size of the $400-\mathrm{km}$ discontinuity and the velocities between 400 and $650 \mathrm{~km}$. The garnet/clinopyroxene ratio can be adjusted in order to obtain appropriate velocities and velocity gradients in the transition region. The high seismic gradient near $500 \mathrm{~km}$ is attributed to the $\beta-\gamma$ phase change and the clinopyroxene-garnetite phase change. The $\mathrm{Al}_{2} \mathrm{O}_{3}$ and orthopyroxene contents control the depth of the latter phase change. High $\mathrm{Al}_{2} \mathrm{O}_{3}$ and low-orthopyroxene eclogites can be ruled out because the transformation pressure of clinopyroxene is too low for these compositions. Opx- and olivine-free eclogite does not have the characteristics required to explain the 400-km discontinuity [Anderson and Bass, 1986]. In their early modeling, Anderson and Bass [1986] used a rather high value for the bulk modulus of majorite. The considerations in this paper, applied to the moduli rather than the derivatives [Anderson, 1987b], suggest that $\mathrm{MgSiO}_{3}$-majorite should have properties similar to pyrope. This is because the ionic radii and elastic properties of ${ }^{\mathrm{vi}} \mathrm{Mg}^{\mathrm{vi}} \mathrm{Si}$ are similar to ${ }^{\mathrm{vi}} \mathrm{Al}_{2}$. This reduces the calculated velocities in the transition region for olivine-orthopyroxene-rich assemblages from those calculated by Anderson and Bass [1986] and permits a higher olivine content for piclocite than considered by these authors. There is still a substantial compressional velocity increase associated with the orthopyroxene-majorite phase change near $400 \mathrm{~km}$ which, when combined with the $\alpha-\beta$ velocity jump, constrains the total olivine plus orthopyroxene to be much less than in pyrolite. Since garnet is stable throughout the transition region and the $\alpha-\beta$ transition only causes a small velocity increase [Weidner, 1986], an appreciable clinopyroxene content is required in order to give a high-velocity gradient in the transition region. A high $\mathrm{Cpx} / \mathrm{Gt}$ content is required in order 
to keep clinopyroxene stable to sufficiently high pressure. This rules out a tholeiitic, or mid-ocean ridge basalt, $\mathrm{Cpx} / \mathrm{Gt}$ ratio for the transition region. Some peridotitic komatiites and garnet pyroxenites (Hawaiian Salt Lake crater "eclogites") have the appropriate characteristics.

Acknowledgments. I thank Craig Bina and Bernard Wood for preprints of their papers. Jay Bass and Tom Duffy provided very useful reviews of a preliminary draft. This research was supported by $\mathrm{Na}$ tional Science Foundation grants EAR-8509350 and EAR-8317623. Division of Geological and Planetary Sciences, California Institute of Technology, contribution 4469.

\section{REFERENCES}

Anderson, D. L., Phase changes in the upper mantle, Science, 157 , 1165-1173, 1967a.

Anderson, D. L., A seismic equation of state, Geophys. J. R. Astron. Soc., 13, 9-30, $1967 b$.

Anderson, D. L., Petrology of the mantle, Mineral. Soc. Am. Spec. Pap., 3, 85-93, 1970 .

Anderson, D. L., A seismic equation of state, II, Shear and thermodynamic properties of the lower mantle, Phys. Earth Planet. Inter., 45, 307-323, 1987a.

Anderson, D. L., Thermally induced phase changes, lateral heterogeneity of the mantle, continental roots, and deep slab anomalies, $J$. Geophys. Res., 92, 13,968-13,980, 1987 b.

Anderson, D. L., and O. L. Anderson, The bulk modulus-volume relationship for oxides, J. Geophys. Res., 75, 3494-3500, 1970.

Anderson, D. L., and J. D. Bass, The transition region of the Earth's upper mantle, Nature, 320, 321-328, 1986.

Anderson, O. L., Equation for thermal expansivity in planetary interiors, J. Geophys. Res., 72, 3661-3668, 1967.

Anderson, O. L., and I. Suzuki, Anharmonicity of three minerals at high temperature: Forsterite, fayalite, and periclase, J. Geophys. Res., 88, 3549-3556, 1983

Bass, J. D., and D. L. Anderson, Composition of the upper mantle: Geophysical tests of two petrological models, Geophys. Res. Lett., $11,229-232,1984$

Bina, C. R., and B. J. Wood, The $400-\mathrm{km}$ discontinuity, Nature, 324 $449-451,1986$

Bina, C. R., and B. J. Wood, The olivine-spinel transitions: Experimental and thermodynamic constraints and implications for the nature of the $400-\mathrm{km}$ seismic discontinuity, J. Geophys. Res., 92, 4853-4866, 1987.

Birch, $F$., The variation of seismic velocities within a simplified Earth model in accordance with the theory of finite strain, Bull. Seismol. Soc. Am., 29, 463-479, 1939.
Birch, F., Thermal expansion at high pressures, J. Geophys. Res., 73, $817-819,1968$

Birch, F., Finite strain isotherm and velocities for single-crystal and polycrystalline $\mathrm{NaCl}$ at high pressures and $300^{\circ} \mathrm{K}, J$. Geophys. Res. $83,1257-1268,1978$

Brillouin, L., Tensors in Mechanics and Elasticity, Academic, Orlando, Fla., 1964.

Burdick, L., and D. L. Anderson, Interpretation of velocity profiles of the mantle, J. Geophys. Res., 80, 1070-1074, 1975.

Fukizawa, A., and $H$. Kinoshita, Shear wave velocity jump at the olivine-spinel transformation in $\mathrm{Fe}_{2} \mathrm{SiO}_{4}$ by ultrasonic measurements in situ, J. Phys. Earth, 30, 245-253, 1982.

Fürth, R., On the equation of state for solids, Proc. R. Soc. London, Ser. $A, 183,87-110,1944$

Gilvarry, J. J., Temperature dependent equations of state of solids, $J$ Appl. Phys., 28, 1253-1261, 1957.

Grüneisen, E., Zustand des festen Körpers, in Handbuch der Physics, vol. 10, pp. 1-52, Springer-Verlag, New York, 1926.

Irifune, T., and A. E. Ringwood, Phase transformations in primitive MORB and pyrolite compositions to $25 \mathrm{GPa}$ and some geophysical implications, in High Pressure Research in Mineral Physics, Geophys. Monogr. Ser., vol. 39, edited by M. H. Manghnani and Y. Syono, pp. 231-242, AGU, Washington, D. C., 1987.

Lees, A. C., M. S. T. Bukowinski, and R. Jeanloz, Reflection properties of phase transition and compositional change models of the 670-km discontinuity, J. Geophys. Res., 88, 8145-8159, 1983.

Sammis, C., D. L. Anderson, and T. Jordan, Application of isotropic finite strain theory to ultrasonic and seismological data, J. Geophys. Res., 75, 4478-4480, 1970.

Sumino, Y., and O. L. Anderson, Elastic constants of minerals, in CRC Handbook of Physical Properties of Rocks, vol. III, edited by R. S. Carmichael, pp. 39-138, CRC Press, Boca Raton, Fla., 1984.

Suzuki, I., and O. L. Anderson, Elasticity and thermal expansion of a natural garnet up to $1000 \mathrm{~K}$, J. Phys. Earth, 31, 125-138, 1983.

Wallace, D. C., Thermodynamics of Crystals, John Wiley, New York, 1972.

Weidner, D. J., A mineral physics test of a pyrolite mantle, Geophys. Res. Lett., 12, 417-420, 1985 .

Weidner, D. J, Mantle model based on measured physical properties of minerals, in Chemistry and Physics of Terrestrial Planets, edited by S. K. Saxena, 251-274, Springer-Verlag, New York. 1986.

Weidner, D. J., and N. Hamaya, Elastic properties of the olivine and spinel polymorphs of $\mathrm{Mg}_{2} \mathrm{GeO}_{4}$ and evaluation of elastic analogues, Phys. Earth Planet. Inter., 33, 275-283, 1983.

D. L. Anderson, Seismological Laboratory, California Institute of Technology, Pasadena, CA 91125.

(Received June 2, 1987 accepted December 10,1987.) 